\title{
Subcortical Input to the Smooth and Saccadic Eye Movement Subregions of the Frontal Eye Field in Cebus Monkey
}

\author{
Jun-ru Tian ${ }^{1}$ and James C. Lynch ${ }^{1,2,3}$ \\ Departments of ${ }^{1}$ Anatomy, ${ }^{2}$ Ophthalmology, and ${ }^{3}$ Neurology, University of Mississippi Medical Center, Jackson, \\ Mississippi 39216-4505
}

\begin{abstract}
We have recently identified two functional subregions in the frontal eye field (FEF) of the Cebus monkey, a smooth eye movement subregion (FEFsem) and a saccadic subregion (FEFsac). The thalamic input to these two subregions was studied and quantified to gain more information about the influence of the cerebellum and basal ganglia on the oculomotor control mechanisms of the cerebral cortex. A recent study using transneuronal transport of virus demonstrated that there are neurons in the basal ganglia and cerebellum that project to the FEFsac with only a single intervening synapse (Lynch et al., 1994). In the present study, we concentrated on the thalamic input to the FEFsem to define possible basal ganglia-thalamuscortex and cerebellum-thalamus-cortex channels of information flow to the FEFsem. We localized the functional subregions using low threshold microstimulation, and retrogradely transported fluorescent tracers were then placed into the FEFsem and FEFsac.
\end{abstract}

The neurons that project to the FEFsem are distributed in (1) the rostral portion of the ventral lateral nucleus, pars caudalis, (2) the caudal portion of the ventral lateral nucleus, pars caudalis, (3) the mediodorsal nucleus, (4) the ventral anterior nucleus, pars parvocellularis, and (5) the ventral anterior nucleus, pars magnocellularis. In contrast, the large majority of neurons that project to the FEFsac are located in the paralaminar region of the mediodorsal nucleus. The FEFsac and FEFsem thus each receive neural input from both basal ganglia-receiving and cerebellar-receiving cell groups in the thalamus, but each receives input from a unique combination of thalamic nuclei.

Key words: pursuit eye movements; saccades; basal ganglia; substantia nigra; cerebellum; frontal eye field; supplementary eye field; thalamus; Cebus monkeys
The frontal eye field (FEF) of macaque monkeys and humans contains two functional subregions. One helps to control rapid gaze shifts from one object of interest to another (saccadic eye movements); the other controls smooth eye movements that are made to track moving objects of interest (pursuit eye movements) (Bruce et al., 1985; Lynch, 1987; Bruce, 1990; Keating, 1991; MacAvoy et al., 1991; Gottlieb et al., 1993, 1994; Berman et al., 1996; Petit et al., 1997). We have recently localized a smooth pursuit subregion (FEFsem) and a saccade subregion (FEFsac) within the FEF in Cebus monkeys (Tian and Lynch, 1996a). Tracer injections into these regions disclosed that each receives its predominant corticocortical input from other regions that are also concerned primarily with initiation and control of eye movements, including the parietal eye field, supplementary eye field, middle superior temporal area, and principal sulcus region (Tian

\footnotetext{
Received Jan. 2, 1997; revised Sept. 11, 1997; accepted Sept. 15, 1997.

This research was supported by Public Health Service Grant 2-R01-EY-04159 and the Joe Weinberg Research Fund (J.C.L.). We are very grateful to Jerome Allison, Becky Massey, Bill Bedinger, Dong-mei Cui, Hao Liu, and David Lynch for their assistance in the experiments, data analysis, and illustrations; to Sandy Ruckstuhl for help in editing this manuscript; and to the personnel of the University of Mississipp Medical Center Television Studio for their assistance in measuring the eye movements. We thank Dr. Peter Strick for assistance in defining thalamic nuclear borders in Cebus monkeys, Drs. Peter Strick and Gregory Mihailoff for helpful comments on earlier versions of this manuscript and Dr. James Hutchins for assistance in neurohistochemical procedures.

This material has been presented by J.-R. T. in partial fulfillment of the requirements for the degree of Doctor of Philosophy.

Correspondence should be addressed to Dr. James C. Lynch, Department of Anatomy, University of Mississippi Medical Center, 2500 North State Street, Jackson, MS 39216-4505.

Copyright (C) 1997 Society for Neuroscience $\quad 0270-6474 / 97 / 179233-15 \$ 05.00 / 0$
}

and Lynch, 1996b). The FEFsem and FEFsac each receive projections from distinctive subregions within these other eye fields. We have proposed that these fields comprise nodes in a cortical network that function primarily in parallel to control purposive eye movements (Tian and Lynch, 1996b).

In addition to the influence of neural information from other cortical regions, the execution of successful eye movements depends heavily on input from the basal ganglia and cerebellum to cortical motor regions. Disorders of the basal ganglia, such as Parkinson's disease and Huntington's disease, produce eye movement disorders (Starr, 1967; Leigh et al., 1983; White et al., 1983; Lasker et al., 1987, 1988; Leigh and Zee, 1991; Tian et al., 1991), as do diseases and injuries that affect the cerebellum (Holmes, 1917; Westheimer and Blair, 1973; Zee, 1982; Lisberger et al., 1987; Keller, 1989; Pierrot-Deseilligny et al., 1990; Keller and Heinen, 1991; Leigh and Zee, 1991).

Recent evidence suggests that the basal ganglia and cerebellum exert their influence on cortical motor regions via highly specific pathways that are relayed through the thalamus, with each cortical area receiving a unique mixture of thalamocortical input (Alexander et al., 1986, 1990; Holsapple et al., 1991; Hoover and Strick, 1993; Lynch et al., 1994; Rouiller et al., 1994; Matelli and Luppino, 1996). However, the thalamocortical input to functionally identified subregions within a single cortical oculomotor field has not been studied previously.

The present experiments were designed to investigate and quantify the thalamocortical input to two oculomotor areas in the cortex that are adjacent to each other and that receive parallel input from four other cortical oculomotor areas but that control 
very different types of eye movements. It was possible that the thalamocortical input to these areas would be relatively parallel, originating in different subregions of the same thalamic nuclei. However, we found the thalamic input to the FEFsem originated in a very different set of thalamic nuclei than did the input to the FEFsac. This suggests that the basal ganglia and cerebellum make quite different contributions to the control of pursuit and saccadic eye movements, respectively.

Parts of this paper have been published previously in an abstract (Tian et al., 1995)

\section{MATERIALS AND METHODS}

Three adult male Cebus apella monkeys, weighing from 3.0 to $3.5 \mathrm{~kg}$, were used in the present study. In three hemispheres, the FEFsem was localized and defined with intracortical microstimulation at low levels ( $\leq$ $50 \mu \mathrm{A}$ ); in four hemispheres, the FEFsac was similarly defined. A new anesthetic agent, Telazol (tiletamine $\mathrm{HCl}$ with zolazepam $\mathrm{HCl}$; Robbins Scientific, Sunnyvale, CA) (Schobert, 1987), permitted microstimulationinduced smooth eye movements to be discriminated reliably from saccadic eye movements, so the localization of the FEFsem did not require the months of behavioral training and recording that such localizations normally require in alert, behaving monkeys (Tian and Lynch, 1995, 1996a). Different retrogradely transported fluorescent dyes were placed within these functionally defined subregions to study the subcortical, especially the thalamocortical, inputs to the FEFsem and FEFsac. Two additional areas near the FEF, the supplementary eye field (SEF) and the hand/arm region of the dorsal premotor cortex (PMd), were also injected in one hemisphere. The methods used in this study have been described previously in detail (Tian and Lynch, 1995, 1996a,b) and will be summarized here.

Surgical procedures. All surgeries were performed under sterile conditions, following National Institutes of Health guidelines and a research protocol that was reviewed and approved by the Institutional Animal Care and Use Committee. Most animals were pretreated with dexamethasone $(0.5 \mathrm{mg} / \mathrm{kg}$, i.m. $)$ and atropine sulfate $(0.04 \mathrm{mg} / \mathrm{kg}$, i.m.) just before surgery. A head holder appliance was fixed to the skull in a separate procedure. For the head holder installation, each animal was initially anesthetized with Ketamine $(10 \mathrm{mg} / \mathrm{kg}$, i.m.); surgical anesthesia was maintained with intravenous pentobarbital sodium. For the surgery during acute mapping experiments, each animal was anesthetized with only Telazol (initial dose, $20-30 \mathrm{mg} / \mathrm{kg}$, i.m.; supplemental dose, 5-10 mg/kg, i.m.). Body temperature was maintained with a heating pad. Vital signs were monitored, and antibiotics (intramuscular Rocephin or Cefazolin) were given during surgery and recovery.

Electrical stimulation procedures. Animals were immobilized during acute microstimulation mapping experiments by light doses of Telazol. Telazol anesthesia, at optimal levels, has very little effect on electrical stimulus threshold (Hoover and Strick, 1993; Lynch et al., 1994; Tian and Lynch, 1995). We have performed extensive comparisons between eye movement parameters during microstimulation in trained, behaving monkeys and eye movements evoked by microstimulation in Telazolanesthetized monkeys and have determined that the velocities and durations of evoked eye movements are only minimally affected by Telazol (Tian and Lynch, 1995, 1996a). Under Telazol anesthesia, eye movements were triggered from the FEF and SEF at thresholds as low as 10 $\mu \mathrm{A}$, and arm and hand movements could be triggered from the premotor cortex and primary motor cortex at thresholds as low as $5 \mu \mathrm{A}$.

Glass-coated Elgiloy or platinum-iridium microelectrodes $(0.5-3 \mathrm{~m} \Omega$ impedance at $1 \mathrm{kHz}$ ) were used. Electrical stimulation consisted of trains

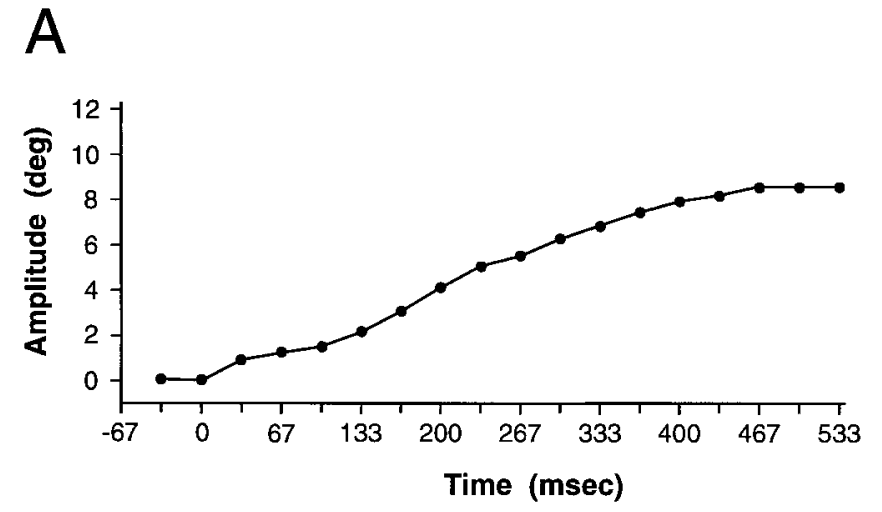

B

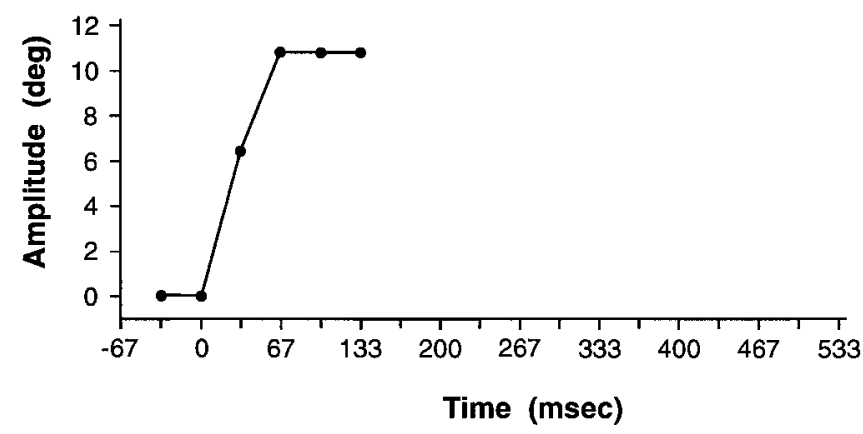

Figure 1. Typical time-amplitude trajectories of eye movements in a Telazol-anesthetized Cebus monkey (C6) are illustrated for smooth $(A)$ and saccadic $(B)$ eye movements. Measurements of eye position were made using video-editing equipment, manually frame by frame. [Modified from Tian and Lynch (1996a) with permission.]

of negative unipolar constant-current pulses. Pulse frequency was 300 $\mathrm{Hz}$, and pulse width was $0.5 \mathrm{msec}$; train duration was normally $100 \mathrm{msec}$ for studying saccadic eye movements and 300-500 msec for studying smooth eye movements. Current was monitored by displaying, on an oscilloscope, the voltage drop across a $1 \mathrm{k} \Omega$ resistor in series with the microelectrode. "Low threshold stimulation" was defined as $\leq 50 \mu \mathrm{A}$. Currents from 50 to $150 \mu \mathrm{A}$ were routinely used to search for elicited eye movements. The threshold level for each stimulation site was then determined to localize the low threshold areas. Each microelectrode placement on the cortex was photographed through the operating microscope used in surgery, and the electrode positions were later reconstructed using a tracing of the pattern of blood vessels on the surface of the cortex as a guide (see Fig. 3; Results). During the course of each microelectrode penetration, we stimulated at intervals of 300-500 $\mu \mathrm{m}$.

Eye movement measurements. During acute cortical mapping experiments, a second operating microscope with an attached video camera was aimed at the eye contralateral to the microstimulation. Eye movements were displayed on a 21 inch television monitor. The total magnification was $12.5 \times$, which aided in the detection and classification of eye movements. Electrically evoked eye movements were recorded on videotape for later verification and analysis (Tian and Lynch, 1995, 1996a). The

\begin{tabular}{|c|c|c|c|c|c|}
\hline Monkey & Hemisphere & FEFsac & FEFsem & SEFsac & PMd \\
\hline $\mathrm{C} 5$ & left & DY & & FS & FR \\
\hline C6 & left & $\mathrm{FB}$ & DY & & \\
\hline C6 & right & FS & FR & & \\
\hline C9 & left & FB & FR & & \\
\hline
\end{tabular}

DY, Diamidino yellow; FB, fast blue; FR, fluoro-ruby; FS, fluorescein conjugated to dextrans; FEFsac, saccadic subregion of the frontal eye field; FEFsem, smooth eye movement subregion of the frontal eye field; SEFsac, saccadic subregion of the supplementary eye field; PMd, hand region of the dorsal premotor cortex. 


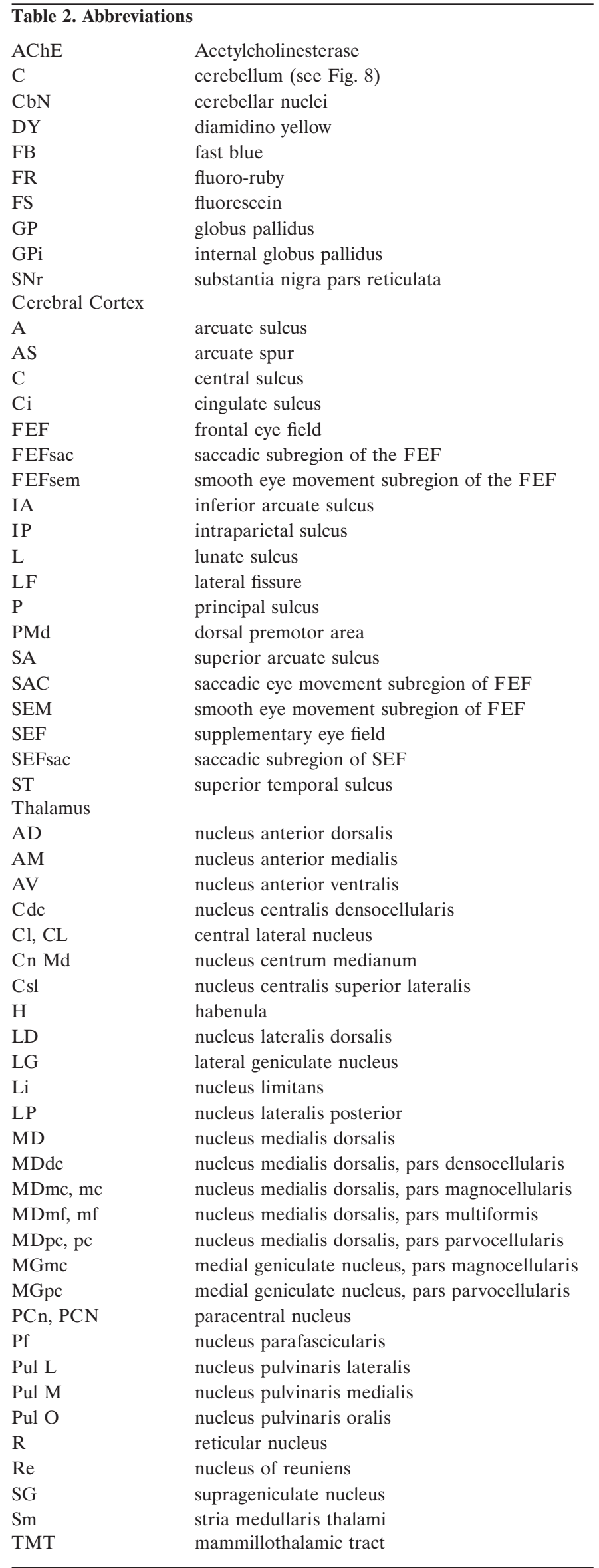

\begin{tabular}{ll}
\hline Table 2. Continued & \\
VA & nucleus ventralis anterior \\
VAmc & pars magnocellularis of VA \\
VApc & pars parvocellularis of VA \\
VL & nucleus ventralis lateralis \\
VLc & nucleus ventralis lateralis, pars caudalis \\
VLcc & caudal portion of VLc \\
VLcr & rostral portion of VLc \\
VLm & nucleus ventralis lateralis, pars medialis \\
VLo & nucleus ventralis lateralis, pars oralis \\
VLps & nucleus ventralis lateralis, pars postrema \\
VPI & nucleus ventralis posterior inferior \\
VPL & nucleus ventralis posterior lateralis \\
VPLc & nucleus ventralis posterior lateralis, pars caudalis \\
VPLo & nucleus ventralis posterior lateralis, pars oralis \\
VPM & nucleus ventralis posterior medialis \\
$X$ & area X in the VL complex \\
\hline
\end{tabular}

amplitude and duration of eye movements were measured with a professional video-editing system, from which the velocities of elicited eye movements could be calculated. This method of measurement permitted the simple quantification of eye movement parameters in the sterile surgery environment necessary for the tracer injections. The $30 \mathrm{~Hz}$ sampling rate of the video equipment caused the duration of saccades to be overestimated. Although these measurements were not as accurate as those that can be provided with the magnetic search coil technique, they were nevertheless more than adequate to permit the statistical differentiation of saccadic and slow eye movements at very high levels of significance ( $p<0.0001$; Tian and Lynch, 1995, 1996a). Typical smooth and saccadic eye movement traces are illustrated in Figure 1.

Tracer injection procedures. After the FEFsem and the FEFsac were localized with low threshold microstimulation, different fluorescent dyes were placed in the functionally defined regions. In control experiments, the SEF and the hand/arm region of PMd were also mapped and injected with fluorescent dyes. Four optically distinct retrogradely transported fluorescent tracers were used in this study. These tracers included fast blue (FB), diamidino yellow (DY), fluororuby [FR; rhodamine conjugated to 10,000 molecular weight (MW) dextrans], and fluorescein (FS) conjugated to 10,000 MW dextrans (Kuypers et al., 1980; Keizer et al., 1983; Nance and Burns, 1990; Schmued et al., 1990). The combination of tracers used in each experimental animal is shown in Table 1 . The tracers FB and DY were used at $2 \%$ suspension in distilled water, and the tracers FR and FS were used at $10 \%$ suspension in distilled water. The latter two tracers were also transported in the anterograde direction, but those results are not reported here. Approximately $0.6 \mu \mathrm{l}$ of each fluorescent dye was placed at each injection site. All tracers were pressure-injected (Hardy and Lynch, 1992), using a 1 or $5 \mu$ l Hamilton syringe. Each injection was made over a $5 \mathrm{~min}$ period. Another $10 \mathrm{~min}$ were allowed to elapse before removing the injection needle from the injection site to minimize the spread of the injected tracers along the needle track.

Histology procedures. Survival times for the four hemispheres used in this study were $15,19,14$, and $14 \mathrm{~d}$. Each monkey then received a lethal dose of pentobarbital sodium and was perfused transcardially with heparinized saline and $4 \%$ formaldehyde in $0.1 \mathrm{~m}$ phosphate buffer. Brains were exposed and blocked stereotaxically in the coronal plane. Brain blocks were stored in $4 \%$ formaldehyde and increasing concentrations of sucrose. They were then frozen and sectioned at $50 \mu \mathrm{m}$ in the coronal plane using a sliding microtome. One series of sections at $250 \mu \mathrm{m}$ intervals was mounted and coverslipped for fluorescence study. Alternate sections in another series of sections (adjacent to the fluorescent sections) were stained using cresyl violet or Weil procedures. Some sections were counterstained after the labeled neurons in them had been plotted. In one monkey, sections containing thalamic nuclei were processed with acetylcholinesterase (AChE) histochemistry to aid in the identification of nuclear boundaries.

Neuroanatomical data analysis procedures. Sections were studied with a Leitz Diaplan fluorescence microscope. The labels were highly discriminable because of their different appearances and different optimal excitation wavelengths. FB and DY fluoresce at an excitation wavelength of 

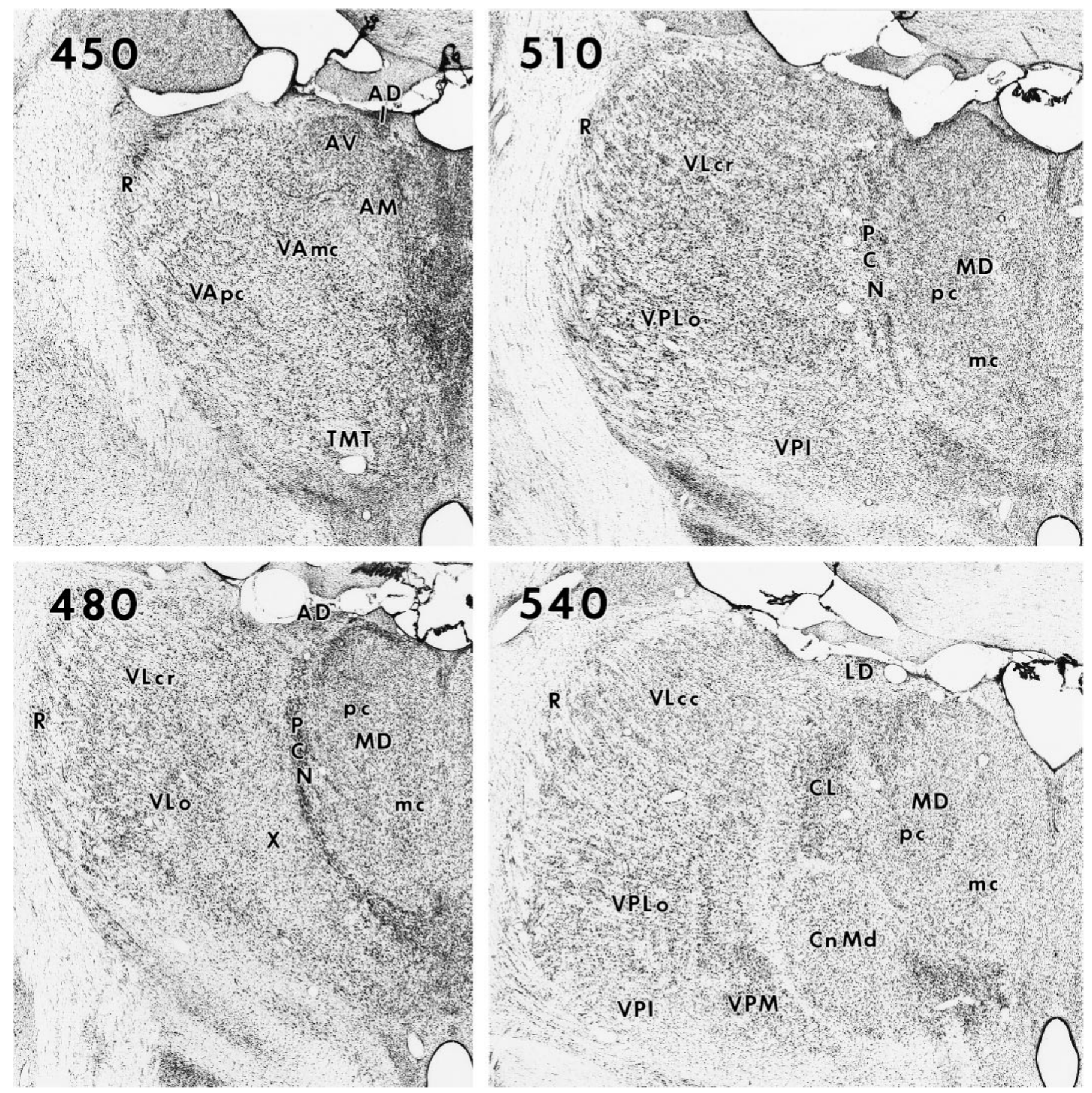

Figure 2. Macrophotographs of cresyl violet-stained sections from the thalamus of Cebus monkey C9. Section 450 is at the most rostral level; 540 is at the most caudal level. See Results for descriptions of nuclei and cytoarchitectural features. $A D$, Anterior dorsalis; $A M$, anterior medialis; $A V$, anterior ventralis; $C L$, central lateral nucleus; $C n M d$, centrum medianum; $L D$, lateralis dorsalis; $M D$, medialis dorsalis; $M D m c$ or $m c$, medialis dorsalis, pars magnocellularis; $M D p c$ or $p c$, medialis dorsalis, pars parvocellularis; $P C N$, paracentral nucleus; $R$, reticular nucleus; $T M T$, mammillothalamic tract; $V A m c$, ventralis anterior, pars magnocellularis; $V A p c$, ventralis anterior, pars parvocellularis; $V L c c$, caudal portion of ventralis lateralis, pars caudalis; $V L c r$, rostral portion of ventralis lateralis, pars caudalis; $V L o$, ventralis lateralis, pars oralis; $V P I$, ventralis posterior inferior; $V P L o$, ventralis posterior lateralis, pars oralis; $V P M$, ventralis posterior medialis; $X$, area $X$ in the ventral lateral complex.

$360 \mathrm{~nm}$. FB filled the cytoplasm of the neuron cell body and appeared bright blue. DY filled only the nucleus of the neuron cell body and appeared yellow-green. Neurons labeled by FR exhibited a characteristic bright red filling of the soma and proximal dendrites at a wavelength of 530-560 nm, whereas FS-labeled neurons displayed a yellow-green cytoplasm at a wavelength of $495-520 \mathrm{~nm}$.

The localization of the injection sites has been described previously in detail (Tian and Lynch, 1996b). The filled portions of the injection sites shown in Results (see Figs. 4, 5) represent the dense core of the injection regions immediately surrounding the needle track, and the dashed line surrounding the dense core represents the region in which the fluorescence was too intense for individual cells to be distinguished. The effective dye uptake zones have been demonstrated to be restricted approximately to the region of tissue damage produced by the passage of 

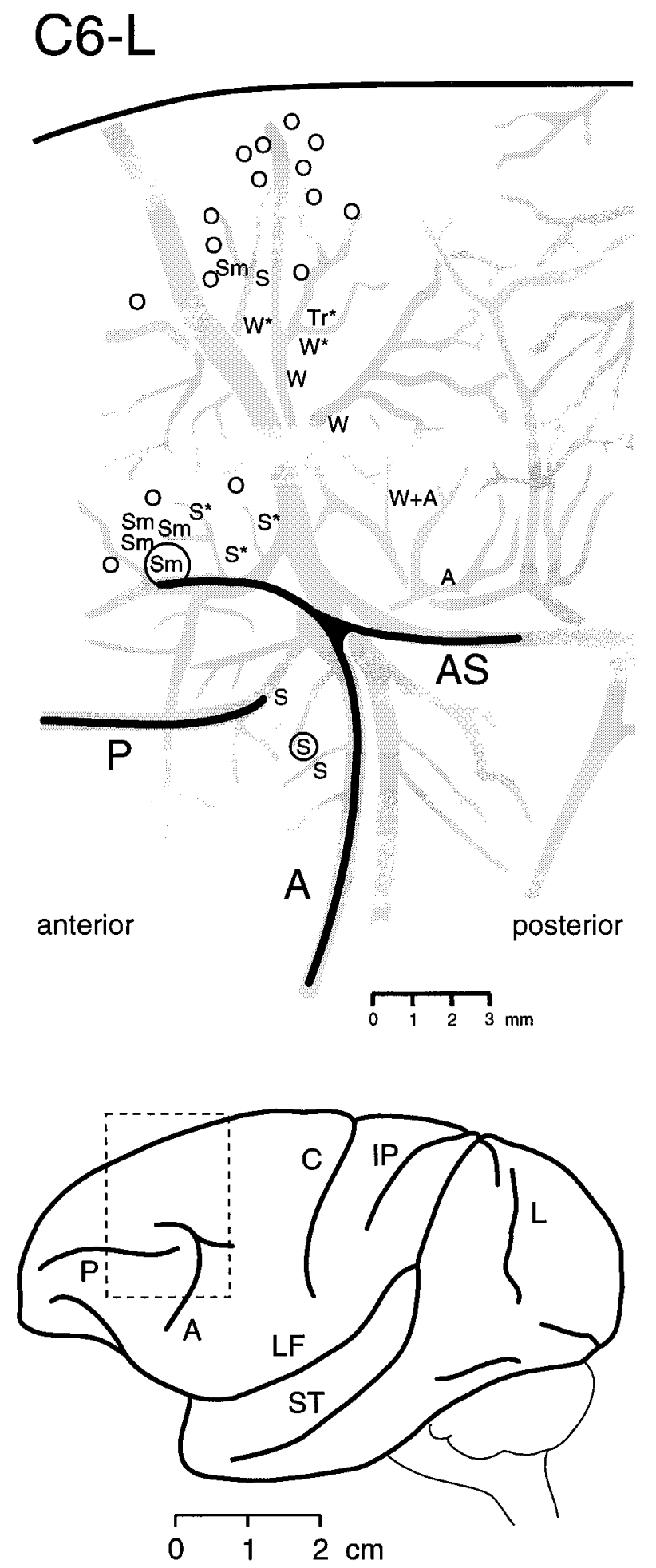

Figure 3. Top, A typical microstimulation map within a region including the frontal eye field, the supplementary eye field, and the dorsal premotor cortex of monkey C6, left hemisphere (C6-L). The map was reconstructed by projecting and tracing a photograph made through the operating microscope of the cortical blood vessels (gray) and then plotting the position of each electrode penetration from individual electrode placement photographs. The locations where movements were elicited at thresholds $<50 \mu \mathrm{A}$ are indicated by letters: $S$, saccade; $S m$, smooth eye movement; $T r$, trunk muscle contraction; $W$, wrist flexion or dorsiflexion $W+A$, wrist dorsiflexion evoked superficially in cortex plus forearm pronation and abduction evoked deeper in cortex; $A$, supination of forearm;
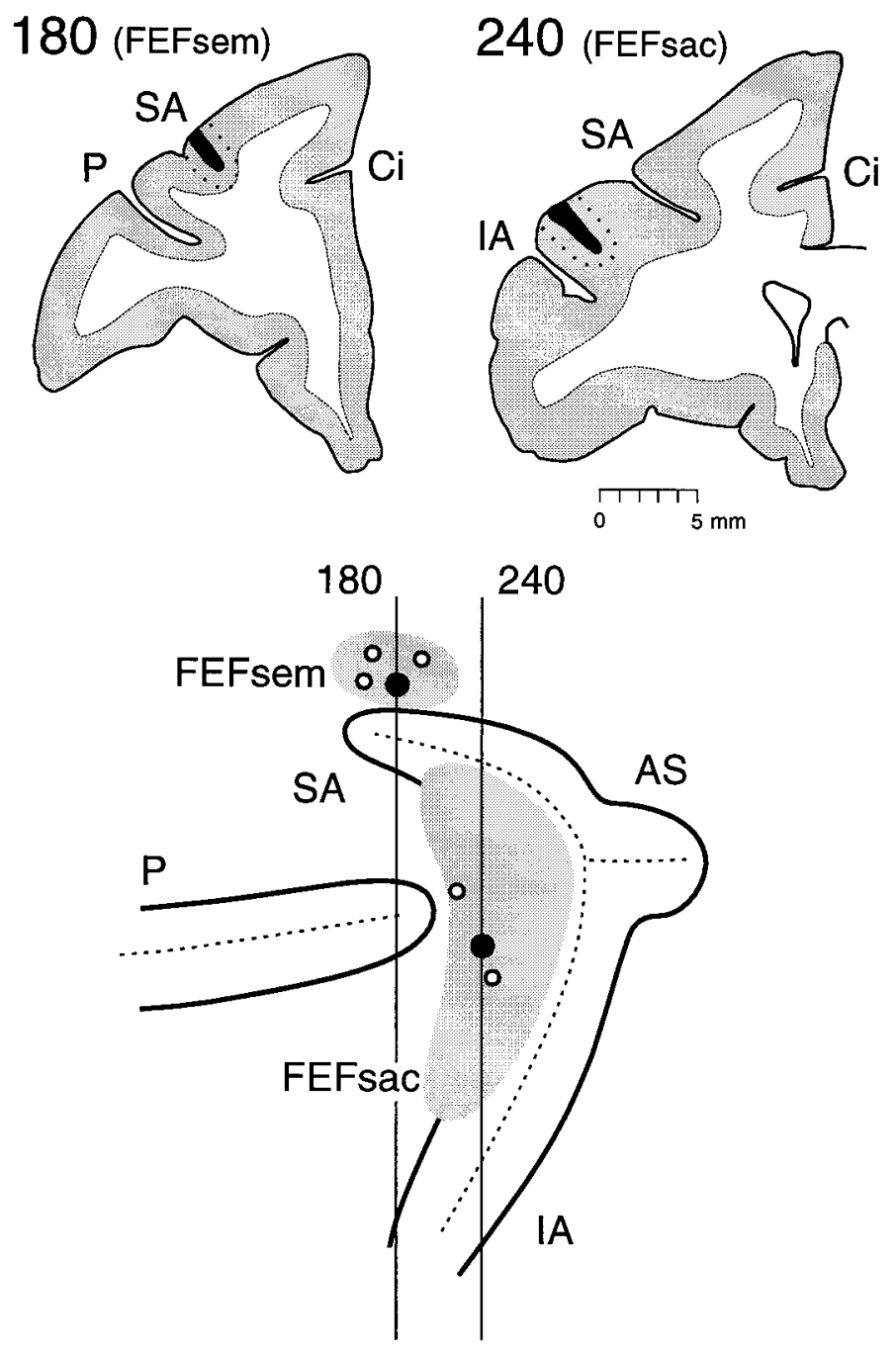

Figure 4. Top, Injection sites in the smooth eye movement subregion of the FEF (section 180) and in the saccadic subregion of the FEF (section 240 ) in monkey C6 on coronal sections. Single placements of different fluorescent tracers are within the gray matter of each functional subregion of the FEF. Bottom, A lateral view of the left hemisphere of monkey C6. The dotted lines indicate the fundi of sulci; the heavy lines indicate the shoulders of sulci. $A S$, Arcuate spur; $C i$, cingulate sulcus; $F E F s a c$, saccadic subregion of the FEF; FEFsem, smooth eye movement subregion of the FEF; $I A$, inferior arcuate sulcus; $P$, principal sulcus; $S A$, superior arcuate sulcus.

the injection needle (Bullier et al., 1984; Condé, 1987). In our experiments, this zone usually had a diameter of $\sim 1 \mathrm{~mm}$. Our injections were usually at least $1 \mathrm{~mm}$ from the edge of a microstimulation-defined functional subregion and at least $4 \mathrm{~mm}$ from any other dye injection. All injections therefore fell entirely within the cortex of the functional area being studied.

Labeled neurons were plotted in every section of the fluorescent series using a Minnesota Datametrics MD3 digitizer system coupled to the microscope stage. After plotting, the coverslips were removed from every

$\leftarrow$

and $O$, no response. An asterisk indicates responses evoked at high threshold $(>50 \mu \mathrm{A})$; a circle around a stimulation point indicates the location of a tracer injection (see also Fig. 4). Bottom, A lateral view of the hemisphere. The dotted rectangle indicates the location of the microstimulation map. $A$, Arcuate sulcus; $A S$, arcuate spur; $C$, central sulcus; $I P$, intraparietal sulcus; $L$, lunate sulcus; $L F$, lateral fissure; $P$, principal sulcus; $S T$, superior temporal sulcus. 


\section{C5-L}
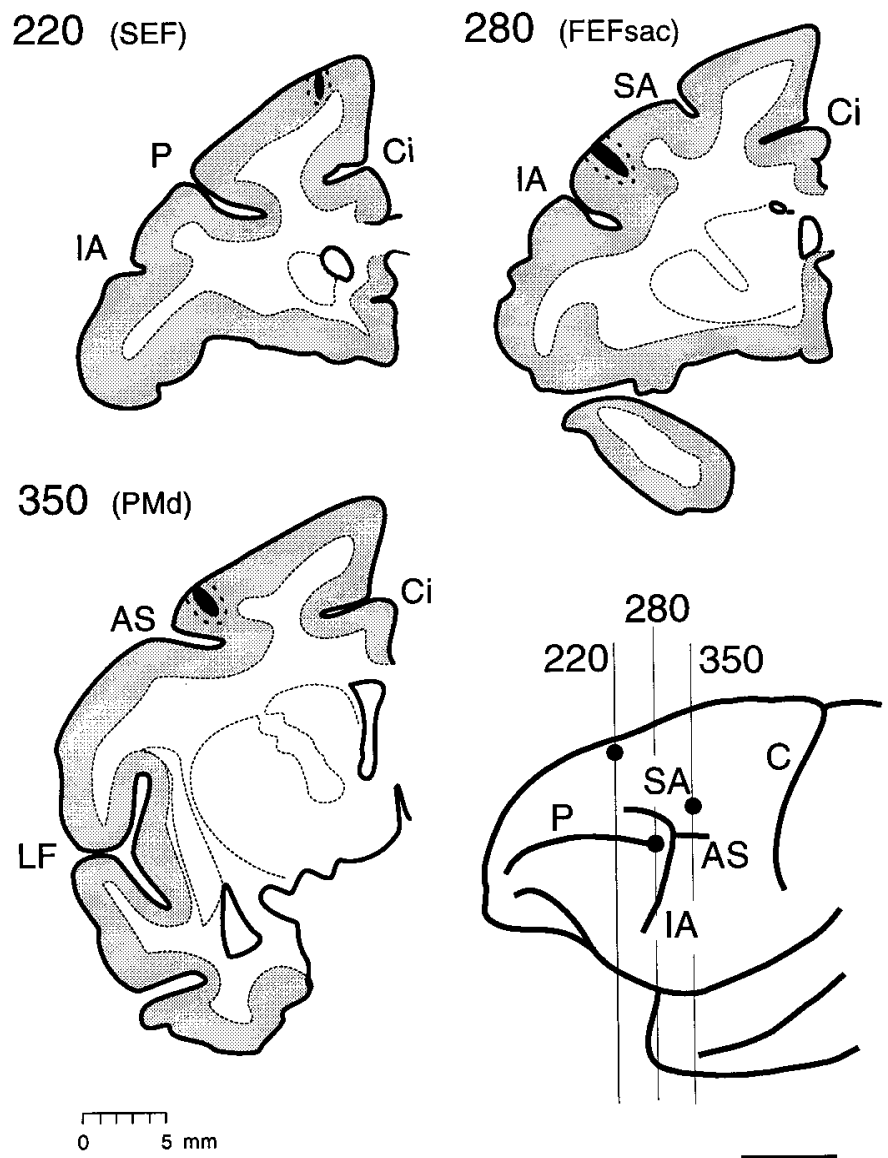

$1 \mathrm{~cm}$

Figure 5. Injection sites of the FEFsac (section 280), the SEF (section 220 ), and the hand area of the PMd (section 350) on coronal sections of monkey C5 $(C 5-L)$. Single placements of different fluorescent tracers are within the gray matter of each functional subregion of the FEF. AS, Arcuate spur; $C$, central sulcus; $C i$, cingulate sulcus; FEFsac, saccadic subregion of the FEF; $I A$, inferior arcuate sulcus; $L F$, lateral fissure; $P$, principal sulcus; $P M d$, dorsal part of premotor cortex; $S A$, superior arcuate sulcus; $S E F$, supplementary eye field.

other fluorescent section, and the sections were stained with cresyl violet. Cytoarchitectural borders were therefore determined on some of the same sections in which labeled neurons had been plotted. The alternate fluorescence sections were not stained, but cytoarchitectural borders were estimated using immediately adjacent sections that had been stained with cresyl violet. Blood vessels were used to align the cresyl violet and fluorescence sections. The cytoarchitectural features of the thalamic nuclei in these sections were studied, and the nuclear borders were traced using a microprojector and a Zeiss Standard research mi- croscope with attached drawing tube. The nuclear borders were then transferred to the plots of the labeled neurons.

The MD3 software provided the capability of counting the labeled cells inside a given region of a plotted section. The desired region of a plot was specified by drawing a polygon around it using a computer mouse. The quantitative measurements of labeled neurons in specific thalamic nuclei in the present study were made using this technique.

The nomenclature that we have used for the thalamic nuclei is based on the atlas of Olszewski (1952). It does, however, incorporate the modifications proposed by Holsapple et al. (1991) that divide VLc into two regions, VLcr and VLcc (see Results). The abbreviations used throughout the text and figures are listed in Table 2.

\section{RESULTS}

Tracers were placed in the FEFsac in four hemispheres and in the FEFsem in three hemispheres. Control injections were made in the SEF and the hand/arm region of the PMd in one hemisphere. We will first describe the salient features of the thalamic nuclei that are important in this study, and then we will describe the placement of the tracers and the distributions of the thalamic neurons that were labeled by these injections.

\section{Cytoarchitecture of thalamic nuclei}

Although atlases of the Cebus thalamus have been published (Eidelberg and Saldias, 1960; Manocha et al., 1968), these atlases do not include the detailed discussion of the thalamic cytoarchitecture that is present in the atlas of the Macaca thalamus of Olszewski (1952). We consequently used cresyl violet, AChE, and Weil methods, in conjunction with Olszewski's atlas (1952) and other recent cytoarchitectural descriptions of the thalamus of Macaca (Asanuma et al., 1983a; Schell and Strick, 1984; Jones, 1985; Ilinsky and Kultas-Ilinsky, 1987; Matelli et al., 1989; Holsapple et al., 1991; Shook et al., 1991), to characterize and delineate the Cebus thalamic nuclei. In general, we have followed the nomenclature of Olszewski (1952), although we have incorporated modifications of the terminology for the divisions of the ventral lateral nucleus that were proposed by Holsapple et al. (1991).

In this study, we focus on the nuclei of the motor thalamus, including the VA, the VL, area X, the VPL, and the MD. The cytoarchitecture, relative position, and relative sizes of these nuclei in the Cebus monkey are quite similar to those of the same nuclei in macaque monkeys (Fig. 2). The VA in both species is divided into two subdivisions, VApc and VAmc. VAmc is characterized by large, darkly staining neurons that are packed in distinct clusters. VApc contains smaller, more lightly staining neurons. The VLo is characterized by darkly staining round or oval neurons that are grouped in distinct clusters. At caudal levels, VLo borders ventrally with the VPLo, borders medially with area X, and borders dorsally with the VLc. The VPLo is distinguished by many large, darkly staining multipolar neurons that are loosely packed and do not form the dense cell clusters seen in VLo. There is also a larger variability in neuron size in VPLo than in VLo. The VLc contains smaller and paler neurons

Figure 6. The origin of thalamic inputs to the FEFsem (blue dots) and FEFsac (red dots) in the left hemisphere of monkey C6 on coronal sections (C6-L). Section 1091 is at the most rostral level, and section 971 is at the most caudal level. The fluorescent tracers FB and DY were injected into the FEFsac and the FEFsem, respectively (see Table 1 and Fig. 4). A total of 31 sections at $250 \mu \mathrm{m}$ intervals were plotted. $A D$, Anterior dorsalis; $A M$, anterior medialis; $A V$, anterior ventralis; $C d c$, centralis densocellularis; $C l$, central lateral nucleus; $C n M d$, centrum medianum; $C s l$, centralis superior lateralis; $H$, habenula; $L D$, lateralis dorsalis; $L G$, lateral geniculate nucleus; $L i$, nucleus limitans; $L P$, lateralis posterior; $M D$, medialis dorsalis; $M D d c$, medialis dorsalis, pars densocellularis; $M D m c$, medialis dorsalis, pars magnocellularis; $M D m f$ or $m f$, medialis dorsalis, pars multiformis; $M D p c$, medialis dorsalis, pars parvocellularis; $M G m c$, medial geniculate nucleus, pars magnocellularis; $M G p c$, medial geniculate nucleus, pars parvocellularis; Pcn, paracentral nucleus; Pf, parafascicularis; Pul L, pulvinaris lateralis; Pul M, pulvinaris medialis; Pul O, pulvinaris oralis; R, reticular (Figure legend continues) 

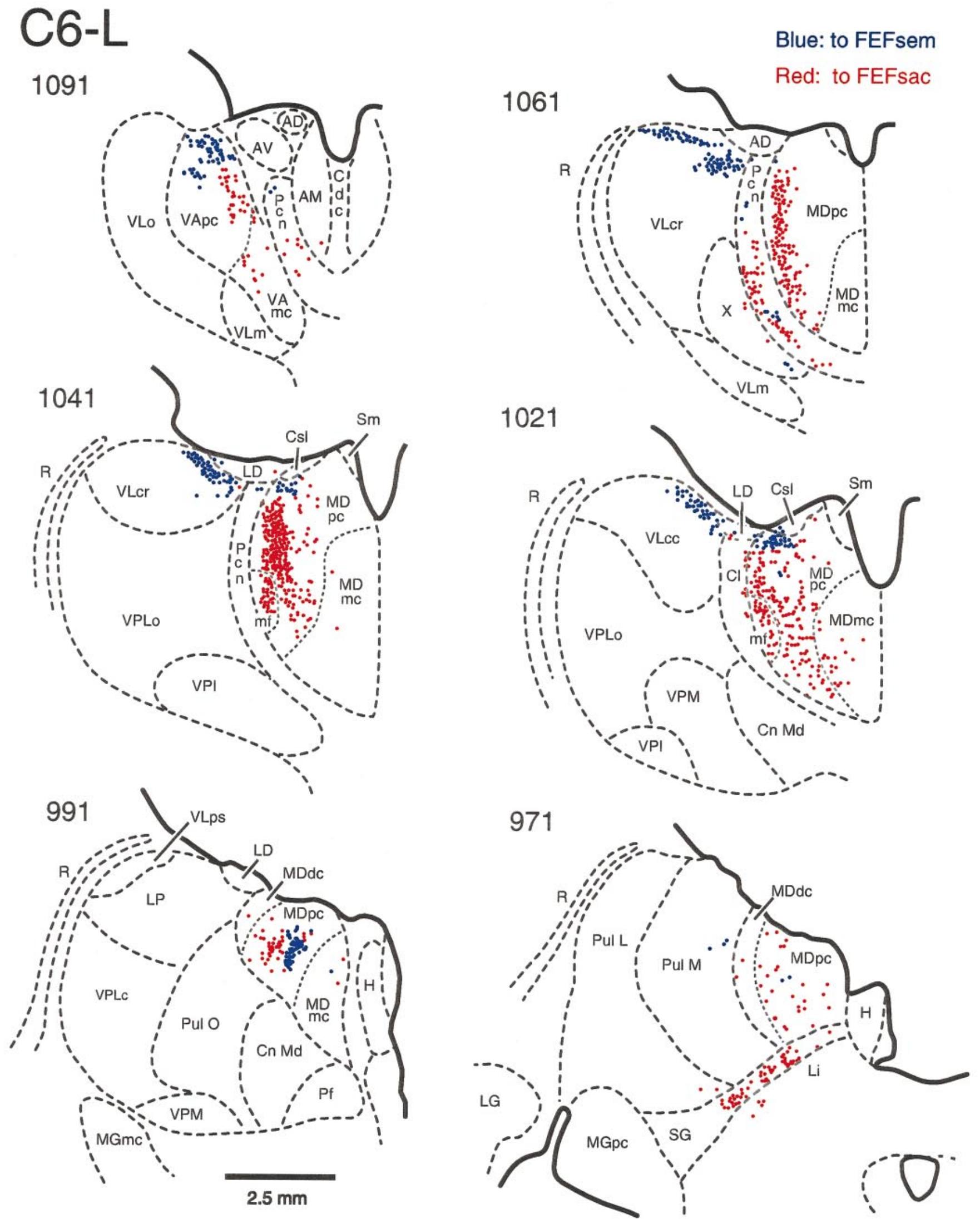

nucleus; $S G$, suprageniculate nucleus; $S m$, stria medullaris thalami; VAmc, ventralis anterior, pars magnocellularis; VApc, ventralis anterior, pars parvocellularis; $V L c$, ventralis lateralis, pars caudalis; $V L c c$, caudal portion of $V L c ; V L c r$, rostral portion of $V L c ; V L m$, ventralis lateralis, pars medialis; $V L o$, ventralis lateralis, pars oralis; VLps, ventralis lateralis, pars postrema; VPI, ventralis posterior inferior; VPLc, ventralis posterior lateralis, pars caudalis; VPLo, ventralis posterior lateralis, pars oralis; VPM, ventralis posterior medialis; $X$, area $X$ in the ventral lateral complex. 
C5-L

1111

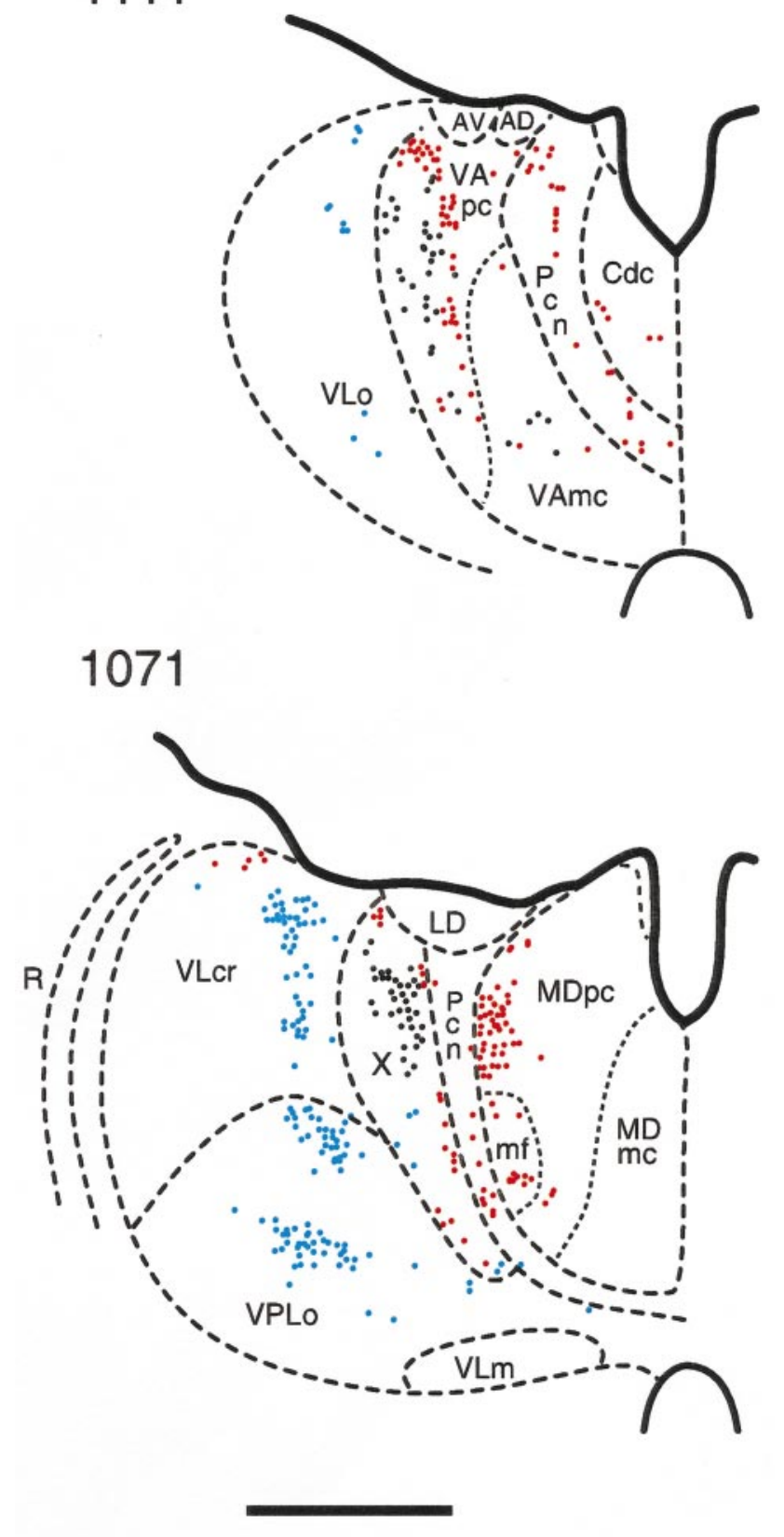

1071

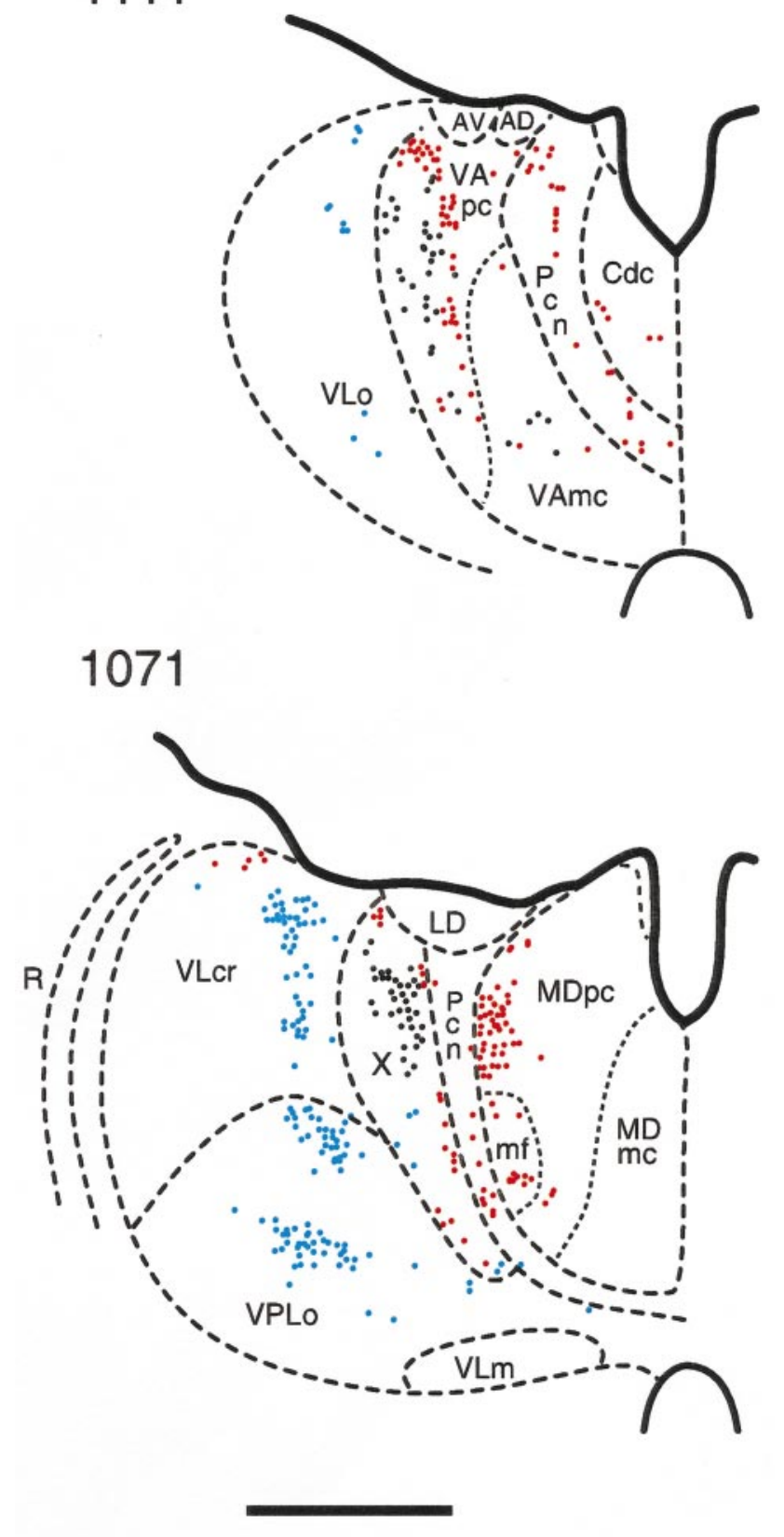

1091

Red: to FEFsac

Black: to SEF

Blue: to PMd (hand)

$2.5 \mathrm{~mm}$

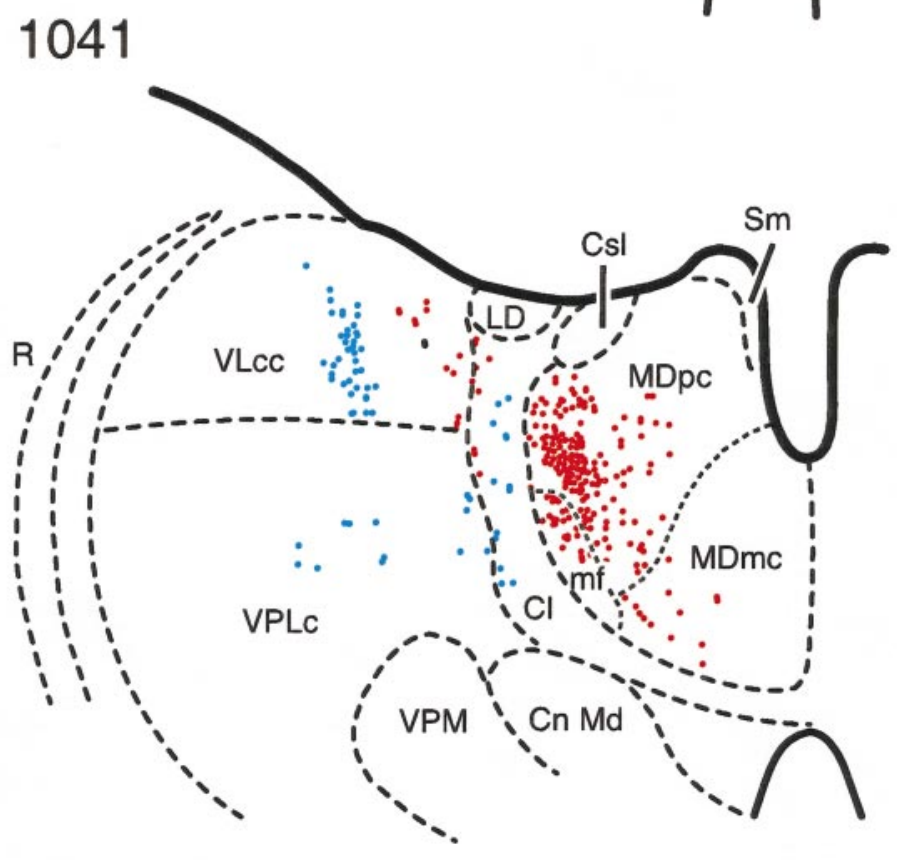

Figure 7. The origin of thalamic inputs to the FEFsac, $S E F$, and $P M d$ in the left hemisphere of monkey C5 on coronal sections (C5-L) (see Table 1 for fluorescent tracers used in these injections). Section 1111 is at the most rostral level, and section 1041 is at the most caudal level. A total of 31 sections at $250 \mu \mathrm{m}$ intervals were plotted. Red dots indicate the neurons labeled from an injection site in the FEFsac; black dots indicate the neurons labeled from an injection site in the $S E F$; and light blue dots indicate the neurons labeled from an injection site of the $P M d$ (hand). $A D$, Anterior dorsalis; $A V$, anterior ventralis; $C d c$, centralis densocellularis; $C l$, central lateral nucleus; $C n M d$, centrum medianum; $C s l$, centralis superior lateralis; $L D$, lateralis dorsalis; $M D m c$, medialis dorsalis, pars magnocellularis; $m f$, medialis dorsalis, pars multiformis; $M D p c$, medialis dorsalis, pars parvocellularis; Pcn, paracentral nucleus; $R$, reticular nucleus; $R e$, nucleus of reuniens; Sm, stria medullaris thalami; VAmc, ventralis anterior, pars magnocellularis; VApc, ventralis anterior, pars parvocellularis; $V L c$, ventralis lateralis, pars caudalis; $V L c c$, caudal portion of $V L c$; $V L c r$, rostral portion of $V L c$; $V L m$, ventralis lateralis, pars medialis; $V L o$, ventralis lateralis, pars oralis; VPI, ventralis posterior inferior; VPLc, ventralis posterior lateralis, pars caudalis; VPLo, ventralis posterior lateralis, pars oralis; $V P M$, ventralis posterior medialis; $X$, area $X$ in the ventral lateral complex. 


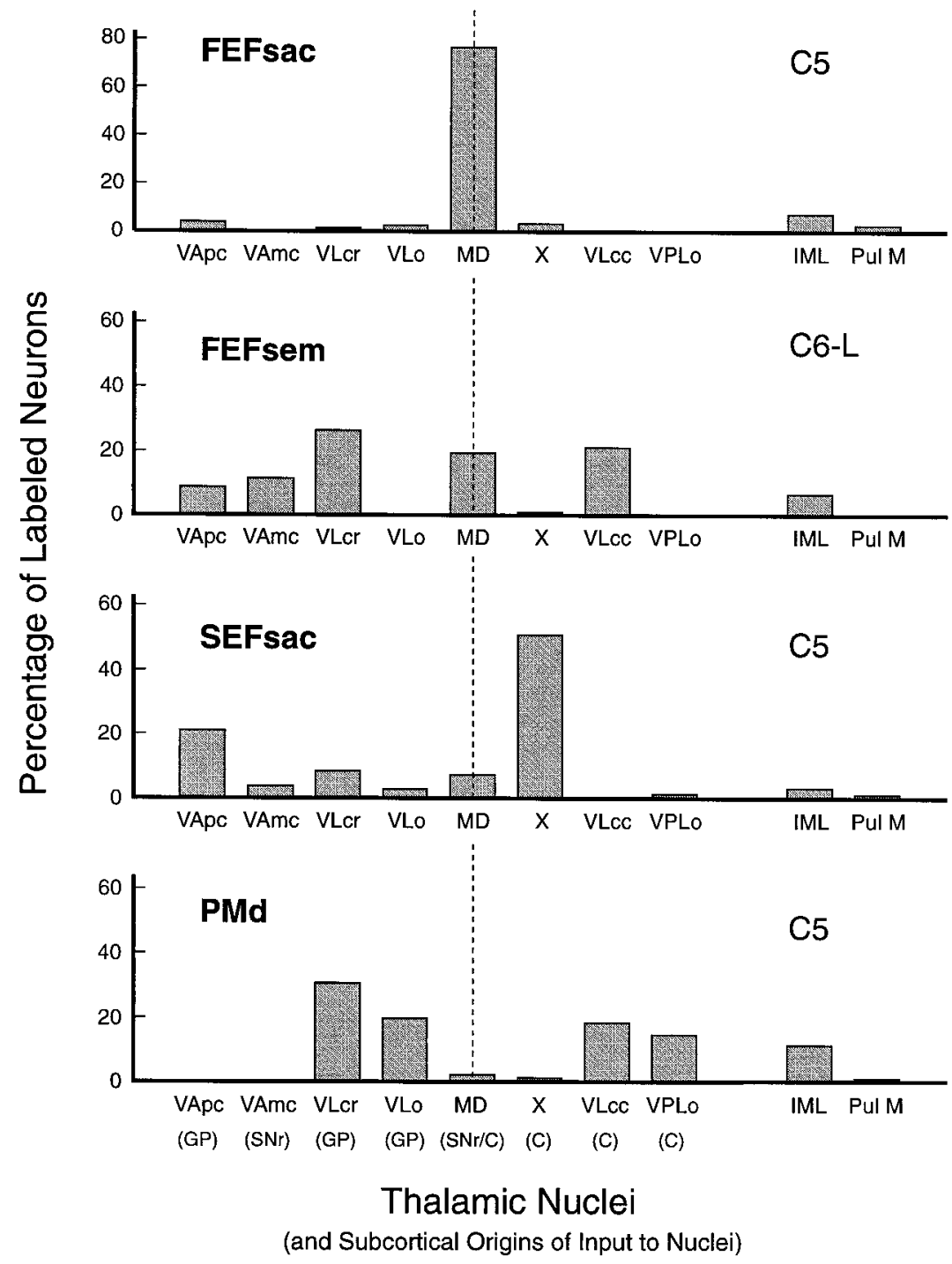

Figure 8. Quantitative comparison of distribution patterns of labeled neurons in thalamic nuclei from the four cortical injection sites. Labeled neurons were counted within the cytoarchitectural boundaries of 31 sections spaced at $250 \mu \mathrm{m}$ intervals in monkeys C5 and C6. Each graph illustrates the percentage, in each nucleus, of the total number of neurons labeled by that particular injection. The thalamic nuclei are arranged on the $x$-axis so that regions that receive input from the internal segment of the globus pallidus and the pars reticulata of the substantia nigra are on the left of the vertical dashed line and the nuclear regions that receive input from the cerebellar nuclei are on the right of the dashed line. The medial dorsal nucleus receives input from both the basal ganglia and the cerebellum. Intralaminar nuclei (Pcn and $\mathrm{Cl})$, indicated by $I M L$, and the Pul $M$ are not included in the basal ganglia versus cerebellum distribution dichotomy. A total of 5692 neurons were labeled by the FEFsac injection, 2876 by the FEFsem injection, 460 by the SEFsac injection, and 1288 by the $P M d$ injection. $C$, Cerebellum, predominantly via the dentate nucleus; FEFsac, saccadic subregion of the frontal eye field; FEFsem, smooth eye movement subregion of the frontal eye field; $G P$, globus pallidus; $I M L$, intralaminar nuclei; $M D$, medialis dorsalis; $P M d$, hand region of the dorsal premotor cortex; Pul M, pulvinaris medialis; $S E F$ $s a c$, saccadic subregion of the supplementary eye field; $S N r$, substantia nigra pars reticularis; VAmc, ventralis anterior, pars magnocellularis; $V A p c$, ventralis anterior, pars parvocellularis; $V L c c$, caudal portion of ventralis lateralis, pars caudalis; $V L c r$, rostral portion of ventralis lateralis, pars caudalis; VLo, ventralis lateralis, pars oralis; VPLo, ventralis posterior lateralis, pars oralis; $X$, area $X$ of ventral lateral complex. than those in VLo and VPLo. VLc has a relatively homogeneous appearance, with neurons of more uniform size than in VPLo and without the clustering seen in VLo. Area $X$ is a welldelineated zone of small, lightly staining neurons with a very homogeneous appearance. MD is easily distinguished from the other nuclei by the internal medullary lamina and the darkly staining neurons of the adjacent intralaminar nuclei. Four subdivisions of MD are commonly distinguished in macaque: MDpc, MDmc, MDmf, and MDdc (Olszewski, 1952; Goldman-Rakic and Porrino, 1985; Barbas et al., 1991). We have found the same subdivisions to be clearly distinguishable in the Cebus monkey, although MDmf is not as easily delineated as in macaque.

Holsapple et al. (1991) have divided the VLc into two subdivisions, VLcr and VLcc, on the basis of differing connectivity with the cerebellum and basal ganglia. This is an important distinction because VLcr receives a major input from the globus pallidus (Kuo and Carpenter, 1973; DeVito and Anderson, 1982), whereas the predominant input to VLcc is from the cerebellum (Percheron, 1977; Stanton, 1980; Kalil, 1981; Asanuma et al., 1983b). There are no clear cytoarchitectural differences between VLcr and VLcc, but the anatomical studies cited above suggest that VLcr lies rostral to anterior level 7.1 in Olszewski's atlas (1952), which corresponds approximately to anterior level 7.5 in the Eidelberg and Saldias atlas of the Cebus monkey (1960) and approximately to section 520 in monkey C9 of the present study (just posterior to section 510 in Fig. 2).

\section{Tracer placements}

The localization of the major functional regions in the periarcuate cortex using microstimulation has been described previously in detail (Tian and Lynch, 1995, 1996a). In these experiments, a limited number of microelectrode penetrations were made in most animals to localize each tracer placement definitively within the boundaries of the respective functional region, while preserving, as much as possible, the integrity of the tissue for later cytoarchitectural study (Fig. 3). The smooth eye movement subregion was reliably located in a small area classically defined as $6 \mathrm{~A} \beta$ (Vogt and Vogt, 1919) and more recently as 6DR (Barbas and Pandya, 1987) or F7 (Matelli et al., 1991). This region is in the posterior shoulder of the arcuate sulcus, near its medial tip (Figs. 3, 4). The saccadic subregion of the FEF in Cebus was localized on the anterior bank of the arcuate sulcus and the rostrally adjacent surface cortex, in areas 8a and 45 of Walker (1940) (Figs. 3, 4; see also Tian and Lynch, 1996a, their Figs. 3, 4, 5).

Typical injection sites in the FEFsac and the FEFsem are illustrated in Figure 4. The shaded areas in the drawing of the 
Figure 9. A, Comparison of the thalamic distributions of FEFsac-labeled neurons in three monkeys. $B$, Comparison of the thalamic distributions of FEFsem-labeled neurons in two monkeys. Each graph illustrates the percentage, in each nucleus, of the total number of neurons labeled by that particular injection. In the inset in $A$, the numbers (5, 6, and 9) show the relative positions of the three FEFsac injection sites on a standardized drawing of the arcuate sulcus region for monkeys C5, C6, and C9, respectively. Tracers were DY in C5, FB in $\mathrm{C} 6$, and $\mathrm{FB}$ in $\mathrm{C} 9$. In the inset in $B$, the two circles indicate the relative positions of the FEFsem injections in monkeys C6 and C9. Tracers were DY in C6 and FR in C9. The thalamic nuclei are arranged on the $x$-axis so that regions that receive input from the internal segment of the globus pallidus and the pars reticulata of the substantia nigra are on the left of the $M D$ and the nuclear regions that receive input from the cerebellar nuclei are on the right of the $M D$. The medial dorsal nucleus receives input from both the basal ganglia and the cerebellum. $A$, Arcuate sulcus; $C L$, central lateral nucleus; $L i$, nucleus limitans; $M D$, medialis dorsalis; $P$, principal sulcus; $P c n$, paracentral nucleus; $P u l M$, pulvinaris medialis; $V A m c$, ventralis anterior, pars magnocellularis; $V A p c$, ventralis anterior, pars parvocellularis; $V L c c$, caudal portion of ventralis lateralis, pars caudalis; $V L c r$, rostral portion of ventralis lateralis, pars caudalis; $V L o$, ventralis lateralis, pars oralis; VPLo, ventralis posterior lateralis, pars oralis; $X$, area $X$ in the ventral lateral complex.
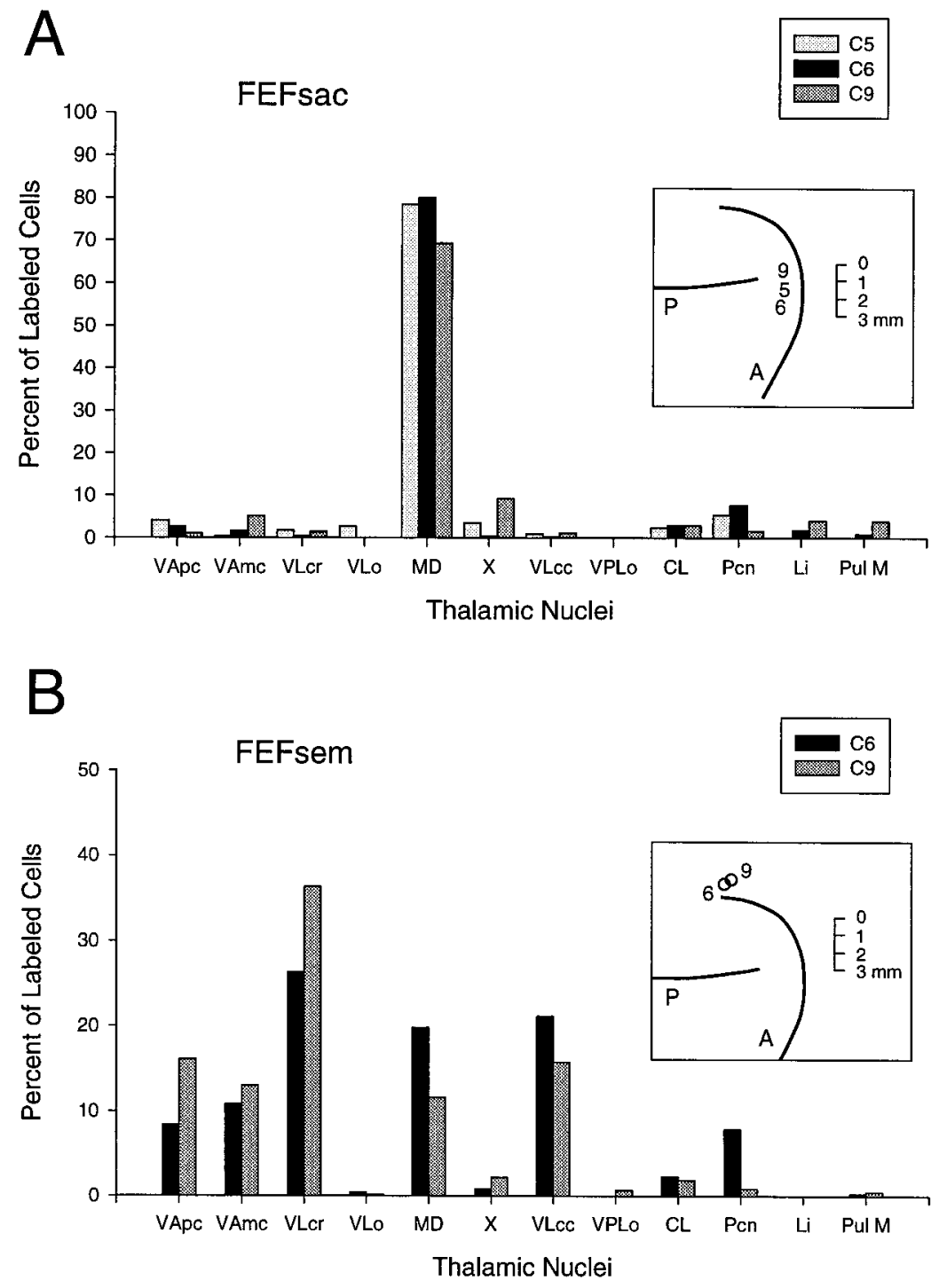

VAmc. Throughout the anteroposterior extent of VLc, a large group of labeled neurons was tightly clustered in the most dorsal part of the nucleus. The FEFsem-labeled neurons in MD were predominantly clustered in the most dorsal portion of MDpc, and their distribution overlapped only slightly with that of FEFsaclabeled neurons. Only in the most posterior portion of MD were the FEFsem and FEFsac neurons somewhat intermixed (sections 991 and 971). Neurons labeled from the FEFsem injections were also scattered in $\mathrm{Pcn}$ and $\mathrm{Cl}$. This distribution was reasonably consistent in two different monkeys using two different tracers (see Fig. 9B).

Thalamic input to the saccadic eye movement subregion of the FEF

Neurons labeled by injections in the FEFsac were much more heavily concentrated in the paralaminar region of MD (both MDmf and MDpc) than in any other thalamic nucleus (Figs. 6, 7, red dots; see also Figs. 8, 9A). Descriptions of the size of the multiform region of $\mathrm{MD}(\mathrm{MDmf})$ in macaques have ranged from relatively small (Goldman-Rakic and Porrino, 1985; Barbas et al., 1991) to quite large, incorporating almost the entire paralaminar region (Siwek and Pandya, 1991). In Cebus monkeys, the zone that can be definitely classified as MDmf, with characteristic

\section{VA, and MD (Fig. 6, blue dots; see also Figs. 8, 9B). At rostral levels, labeled neurons were distributed in both the VApc and the \\ Distribution of labeled thalamocortical neurons \\ Thalamic input to the smooth eye movement subregion of the FEF \\ Neurons labeled by injections in the FEFsem were primarily in the most dorsal part of several thalamic nuclei including VLc,}




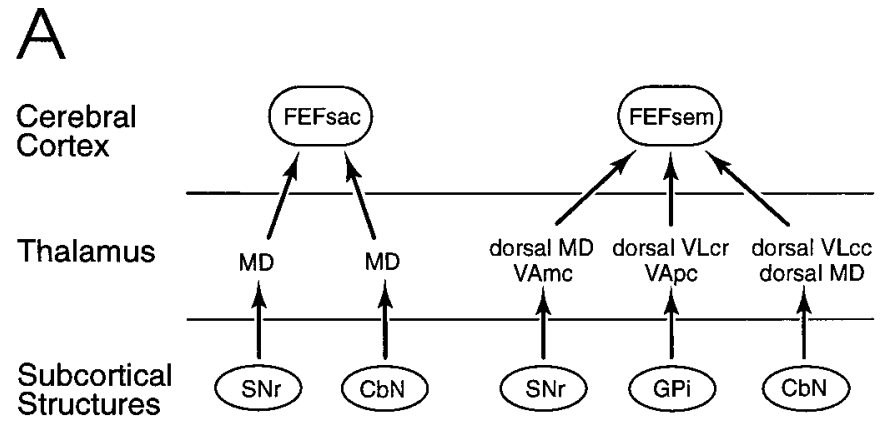

B

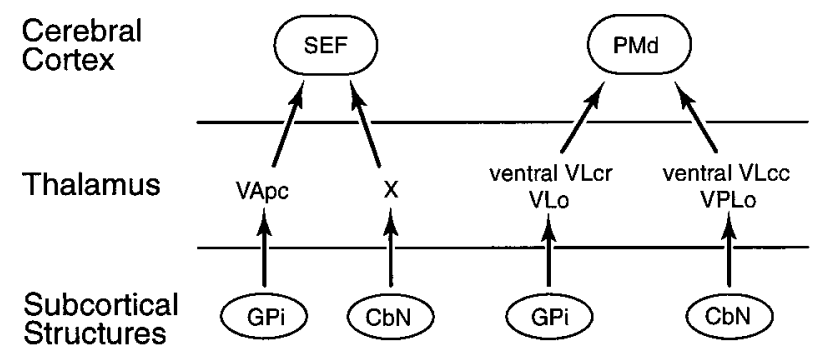

Figure 10. Summary diagram of $G P i$ - and $S N r$-thalamocortical and cerebellothalamocortical connection patterns. $A$, Putative circuits from basa ganglia and cerebellum through thalamic nuclei to the FEFsac and $F E F$ sem. $B$, Putative circuits from basal ganglia and cerebellum through thalamic nuclei to the $S E F$ and $P M d$. Each of the functional areas in the cerebral cortex receives a major neural input from both a basal gangliareceiving and a cerebellar-receiving cell group in the thalamus. It is proposed that some neurons from the basal ganglia and cerebellar nuclei synapse on thalamic neurons that, in turn, project to the cortical eye fields. However, this specific connectivity has thus far been confirmed with transneuronal transport experiments only in the case of the FEFsac (Lynch et al., 1994). The terms "dorsal" and "ventral" are used with the $V L c r$ and $V L c c$ nuclei to emphasize the fact that even though both the FEFsem and the $P M d$ receive input from these two nuclei, the respective pathways originate in separate subregions of these nuclei. Similarly, the term "dorsal MD" is used to emphasize that the $M D$ projection to the FEFsem originates in the dorsal-most portion of paralaminar $M D$, whereas the $M D$ projection to the $F E F s a c$ originates relatively more ventrally in paralaminar $M D$. $C b N$, Cerebellar nuclei; $F E F$, frontal eye field; FEFsac, saccadic subregion of the FEF; FEFsem, smooth eye movement subregion of the $F E F$; $G P i$, internal globus pallidus; $M D$, medialis dorsalis; $P M d$, dorsal premotor cortex; $S E F$, supplementary eye field; $S N r$, substantia nigra, pars reticulata; $V A m c$, ventralis anterior, pars magnocellularis; VApc, ventralis anterior, pars parvocellularis; VLcc, caudal portion of ventralis lateralis, pars caudalis; $V L c r$, rostral portion of ventralis lateralis, pars caudalis; VLo, ventralis lateralis, pars oralis; VPLo, ventralis posterior lateralis, pars oralis; $X$, area $X$ in the ventral lateral complex.

large, darkly staining cells, is quite small. Most neurons labeled by FEFsac injections were therefore clearly within the paralaminar zone of MDpc. Labeled neurons were also densely packed within the intralaminar nuclei $\mathrm{Pcn}$ and $\mathrm{Cl}$. Both of these nuclei are known to receive strong projections from the dentate nucleus (Chan-Palay, 1977) and have been implicated in the control of purposeful as well as spontaneous eye movements (Schlag-Rey and Schlag, 1977, 1984; Schlag et al., 1980; Schlag and Schlag-Rey, 1984). A small number of labeled neurons was also observed in VApc, VAmc, VLo, VLc, area X, the medial pulvinar nucleus, and the nucleus limitans (Figs. 8, 9A). This general distribution was remarkably consistent in three different monkeys and for two different tracers (Fig. 9A).

\section{Thalamic input to the SEF and the PMd}

The supplementary eye field and the hand/arm region of the dorsal premotor cortex both lie very close to the smooth eye movement subregion in the Cebus monkey. The thalamic input to both the SEF and the PMd have been studied extensively in the macaque monkey but not in the Cebus. To compare the thalamocortical input to the SEF and the PMd with the thalamocortical input to the closely adjacent FEFsem and also to compare the thalamocortical input to the SEF and the PMd in Cebus with that in Macaca, we made tracer injections in the SEF and the PMd in one hemisphere (Fig. 7).

Most neurons labeled by the SEF dye placement were clustered in area $X$ of the ventral lateral complex (Fig. 7, black dots; see also Fig. 8). Labeled neurons were also observed in the VA nucleus, predominantly in the VApc. Some labeled neurons were seen in VLcr and in MD, a few labeled neurons were scattered within VLo at rostral levels, and a few labeled neurons were also seen in Cl. The SEF thus receives major thalamocortical input from both a basal ganglia target (VApc) and a cerebellar target (X) (Figs. 8, 10).

The majority of the neurons labeled by the PMd dye placement were located in VLo, VLcr, VLcc, and VPLo (Fig. 7, light blue dots; see also Fig. 8). The labeled neurons in VLcr and VLcc were located in general more ventrally in the nucleus than were the clusters of FEFsem neurons that were also observed in V Lcr and VLcc in hemispheres C6-R, C6-L, and C9-L. Thalamocortical neurons that projected to PMd were thus located in target areas of the basal ganglia (VLcr, VLo) as well as in target areas of the cerebellum (VLcc, VPLo) (Figs. 8, 10).

The overall distributions of the cells of origin of the thalamocortical input to the four functionally defined cortical areas studied in these experiments are therefore markedly different from each other (Fig. 8). However, each cortical area receives input from thalamic targets of both the basal ganglia and the cerebellum. The distributions that we have described for neurons that project to FEFsac were consistent in three different animals and with two different tracers (Fig. 9A). The injections in all three of these animals were placed near the middle of the FEFsac (see inset). No reliable differences were seen that were related to the mediolateral positions of the injection sites. However, all three injections were within the middle third of the usual extent of the FEFsac. There was somewhat more variation in the relative distributions of the neurons that projected to the FEFsem (Fig. $9 B)$ than in the distributions of the neurons that projected to the FEFsac (Fig. 9A). Nevertheless, the basic pattern of the FEFsem-neuron distributions was the same for both animals (Fig. 9B).

\section{DISCUSSION}

There is steadily increasing evidence that the neural pathways mediating the influence of the basal ganglia and cerebellum on motor activity in the cerebral cortex are highly specialized and are different for different types of motor behaviors and different cortical areas. In important review papers, Alexander et al. (1986, 1990) have proposed that there are at least four distinct cortexbasal ganglia-cortex "circuits" or "loops": a "motor" loop related to precentral somatomotor cortex, an "oculomotor" loop related to the frontal eye field, a "prefrontal" loop related to dorsolateral prefrontal and lateral orbitofrontal cortex, and a "limbic" loop related to anterior cingulate and medial orbitofrontal cortex. 
Each circuit is thought to involve separate, functionally independent regions of the basal ganglia and thalamus. They have further suggested that within each major circuit there are segregated "channels," each of which subserves one specific aspect of the related function. For example, the globus pallidus contains distinct, spatially segregated populations of neurons that project, respectively, to primary motor cortex, the supplementary motor area, and ventral premotor cortex via separate, nonoverlapping regions within VLo (Hoover and Strick, 1993). Thus, pallidal channels directed to the primary motor cortex may subserve a completely different aspect of motor control than do pallidal channels directed toward the supplementary motor area. Cortical-cerebellar-cortical circuits seem to be similarly specialized. For example, neurons in the most posterior and ventral portion of the dentate nucleus were labeled transneuronally by herpesvirus placed in the FEF (Lynch et al., 1994), whereas dentate neurons labeled by virus placements just anterior to the FEF in adjacent cortical area 46 occupy the middle third of the inferior portion of that nucleus (Middleton and Strick, 1994).

The oculomotor system provides an excellent model to test hypotheses concerning separate channels within a given subcortical-cortical loop circuit. The FEF contains two distinct subregions. One (FEFsem) participates in the control of smooth pursuit eye movements, with the attendant demand for constant feedback control of eye position and velocity (Lynch, 1987; Keating, 1991). The second (FEFsac) participates in the control of saccadic eye movements, which are more nearly all-or-none, precalculated ballistic eye movements (Bruce and Goldberg, 1985; Bruce et al., 1985) and thus do not require neural feedback during the course of an individual movement. The comparison of the thalamic inputs to these two cortical subregions can give important information about the relative participation of the basal ganglia and cerebellum in the function of the FEF in the control of pursuit and saccadic eye movements. However, in macaque monkeys (the usual subject in physiological and anatomical oculomotor studies), the FEFsem is located in the very bottom of the deep arcuate sulcus and thus constitutes a difficult target for accurate tracer injections (MacAvoy et al., 1991; Gottlieb et al., 1993, 1994).

We have recently localized the FEFsem in the Cebus monkey and found it to be on the posterior shoulder of the arcuate sulcus where it can be more accurately injected with anatomical tracers (Tian and Lynch, 1996a). Tracer experiments demonstrated that the FEFsem and the FEFsac are connected in parallel to separate subregions of each of four other cortical eye fields (Tian and Lynch, 1996b). These anatomical results support recent proposals that the cortical control of eye movements is not organized as a serial process, originating in the primary visual cortex and culminating in the frontal eye field, but rather is mediated by two parallel networks of cortical eye fields that control purposeful pursuit and saccadic eye movements in a cooperative way (Lynch, 1992; Barton et al., 1996; Tian and Lynch, 1996b). Similar proposals have been made for corticocortical networks to subserve working memory, spatially guided behavior, and other cognitive functions (Goldman-Rakic, 1988; Selemon and Goldman-Rakic, 1988; Mesulam, 1990; Friedman and Goldman-Rakic, 1994; Bressler, 1995; Klingberg et al., 1997). However, even when a function such as eye movement control is distributed across several nodes in a network, each node probably makes its own special contribution to the function of the network as a whole.

How might the basal ganglia and cerebellar loops affect the FEFsem and FEFsac subregions independently? One obvious difference is that the FEFsem receives a considerably richer input from the globus pallidus targets in the thalamus than does the FEFsac. In the past, most studies of basal ganglia and eye movements have focused on saccadic eye movements (Hikosaka and Wurtz, 1983a,b,c,d; Hikosaka, 1989; Hikosaka and Wurtz, 1989; Kato et al., 1995; Kori et al., 1995). To our knowledge, no recording studies in behaving subhuman primates have looked directly at the role of the basal ganglia in visual pursuit. However, visual pursuit is often impaired in humans with idiopathic Parkinson's disease (White et al., 1983) as well as in humans with MPTP-induced Parkinsonism (Hotson et al., 1986). Furthermore, a recent functional magnetic resonance imaging study has observed increased activity in the putamen of subjects performing visual pursuit tasks but not saccade tasks (Berman et al., 1996) (J. A. Sweeney, personal communication). In our present study, FEFsem injections labeled thalamic targets of both the globus pallidus and $\mathrm{SNr}$, whereas FEFsac injections labeled only a thalamic target of the SNr. This suggests that the caudate, putamen, and globus pallidus play an important role in the control of visual pursuit. Furthermore, because the $\mathrm{SNr}$ projects to thalamic nuclei that, in turn, project to the FEFsem, it may also participate in the control of visual pursuit in addition to its well known role in the control of saccadic eye movements (Hikosaka, 1989; Hikosaka and Wurtz, 1989).

Recent evidence suggests that each functional subregion of the cortical somatomotor system receives input from both the basal ganglia and the cerebellum (Holsapple et al., 1991; Yamamoto et al., 1992; Hoover and Strick, 1993; Rouiller et al., 1994; Matelli and Luppino, 1996). For example, Holsapple et al. (1991) demonstrated that the hand region of primary motor cortex can basal ganglia input via the nucleus ventralis lateralis, pars oralis, and cerebellar input via nucleus ventralis posterior lateralis, pars oralis. Similarly, Matelli and Luppino (1996) have observed that different functional subregions within cytoarchitectural area 6 (premotor and supplementary motor cortex) each receive thalamic input from both basal ganglia relay nuclei and cerebellar relay nuclei in the thalamus.

Our results demonstrate that each of the eye fields of the frontal cortex (FEFsem, FEFsac, and SEF), as well as the dorsal premotor cortex $(\mathrm{PMd})$, receive input from both basal ganglia and cerebellum (Figs. 9, 10). We have demonstrated that the FEFsem receives thalamocortical input from VApc and VLcr, nuclei that receive input from the globus pallidus (Nauta and Mehler, 1966; Kuo and Carpenter, 1973; Kim et al., 1976; DeVito and Anderson, 1982). The FEFsem also receives input from VAmc and MD. These nuclei are targets of the substantia nigra (Carpenter and McMasters, 1964; Carpenter and Strominger, 1967; Carpenter and Peter, 1972; Carpenter et al., 1976, 1981; Ilinsky et al., 1985; Ilinsky and Kultas-Ilinsky, 1987).

The FEFsem also receives a large percentage of its thalamocortical input from VLcc and MD (Figs. 9, 10). These nuclei are targets of cerebellum projections, originating predominantly in the dentate nucleus (Kusama et al., 1971; Kievit and Kuypers, 1972; Kuo and Carpenter, 1973; Batton et al., 1977; Chan-Palay, 1977; Percheron, 1977; Stanton, 1980; Kalil, 1981; DeVito and Anderson, 1982; Asanuma, 1983b,c). The dentate nucleus, in turn, receives its cerebellar input from the hemispheres and paraflocculus (Jansen and Brodal, 1940, 1942; Nagao, 1992; Nagao et al., 1992). In contrast, the fastigial nucleus, which has been intensively studied with respect to eye movement control, has only modest projections to the thalamus (Blanks, 1988; Noda et al., 1990; Leichnetz and Gonzalo-Ruiz, 1996). It does, however, 
have extensive connections to the brainstem oculomotor system (Batton et al., 1977; Gonzalo-Ruiz et al., 1988; Noda et al., 1990; Leichnetz and Gonzalo-Ruiz, 1996). Thus the cerebellar vermis and related fastigial nucleus seem to exert their primary oculomotor influence at the brainstem level, whereas the dentate nucleus and associated cerebellar hemispheres and paraflocculus are the primary participants in the cortex-cerebellum-thalamuscortex circuits.

The predominant input to the FEFsac in Cebus monkeys is from the paralaminar area of the MD nucleus (Figs. 9, 10). This region is known to receive input from the $\mathrm{SNr}$, dentate nucleus of the cerebellum, and superior colliculus (Harting et al., 1980: Ilinsky et al., 1985; Ilinsky and Kultas-Ilinsky, 1987; Yamamoto et al., 1992). Furthermore, recent experiments have demonstrated that herpesvirus placed in the FEF is transported transneuronally to the $\mathrm{SNr}$, the dentate, and the superior colliculus (Lynch et al., 1994). These three structures each have major roles in the control of saccadic eye movements.

In summary, our results demonstrate that both the pursuit and the saccadic subregions of the frontal eye field receive connections from both basal ganglia targets and cerebellar targets in the thalamus. However, the exact pathway taken by the basal gangliathalamus-FEFsem circuit is anatomically distinct from the pathway taken by the basal ganglia-thalamus-FEFsac circuit. Similarly, the cerebellum-thalamus-FEFsem circuit is anatomically distinct from the cerebellum-thalamus-FEFsac circuit.

\section{REFERENCES}

Alexander GE, DeLong MR, Strick PL (1986) Parallel organization of functionally segregated circuits linking basal ganglia and cortex. Annu Rev Neurosci 9:357-381.

Alexander GE, Crutcher MD, DeLong M (1990) Basal gangliathalamocortical circuits: parallel substrates for motor, oculomotor, "prefrontal" and "limbic" functions. In: Progress in brain research, Vol 85 (Uylings HBM, Van Eden CG, Bruin JPC, Corner MA, Feenstra MGP, eds), pp 119-146. New York: Elsevier.

Asanuma C, Thach WT, Jones EG (1983a) Cytoarchitectonic delineation of the ventral lateral thalamic region in the monkey. Brain Res 286:219-235.

Asanuma C, Thach WT, Jones EG (1983b) Distribution of cerebellar terminations in the ventral lateral thalamic region of the monkey. Brain Res 286:237-265.

Asanuma C, Thach WT, Jones EG (1983c) Anatomical evidence for segregated focal groupings of efferent cells and their terminal ramifications in the cerebellothalamic pathway of the monkey. Brain Res Rev 5:267-297.

Barbas H, Pandya DN (1987) Architecture and frontal cortical connections of the premotor cortex (area 6) in the rhesus monkey. J Comp Neurol 256:211-228.

Barbas H, Haswell Henion TH, Dermon CR (1991) Diverse thalamic projections to the prefrontal cortex in the rhesus monkey. J Comp Neurol 313:65-94.

Barton JJS, Sharpe JA, Raymond JE (1996) Directional defects in pursuit and motion perception in humans with unilateral cerebral lesions. Brain 119:1535-1550.

Batton RR, Jayaraman III A, Ruggiero D, Carpenter MB (1977) Fastigial efferent projections in the monkey: an autoradiographic study. J Comp Neurol 174:281-306.

Berman RA, Luna B, McCurtain BJ, Strojwas MH, Voyvodic JT, Thulborn KR, Sweeney JA (1996) fMRI studies of human frontal eye fields. Soc Neurosci Abstr 22:1687.

Blanks RHI (1988) Cerebellum. In: Neuroanatomy of the oculomotor system (Büttner-Ennever JA, ed), pp 225-272. Amsterdam: Elsevier.

Bressler SL (1995) Large scale cortical networks and cognition. Brain Res Rev 20:288-304.

Bruce CJ (1990) Integration of sensory and motor signals in primate frontal eye fields. In: From signal and sense: local and global order in perceptual maps (Edelman GM, Gall WE, Cowan WM, eds), pp 261-314. New York: Wiley-Liss.
Bruce CJ, Goldberg ME (1985) Primate frontal eye fields. I. Single neurons discharge before saccades. J Neurophysiol 53:603-635.

Bruce CJ, Goldberg ME, Bushnell MC, Stanton GB (1985) Primate frontal eye fields. II. Physiological and anatomical correlates of electrically evoked eye movements. J Neurophysiol 54:714-734.

Bullier J, Kennedy H, Salinger W (1984) Bifurcation of subcortical afferents to visual areas 17, 18, and 19 in the cat cortex. J Comp Neurol 228:309-328.

Carpenter MB, McMasters RE (1964) Lesions of the substantia nigra in the rhesus monkey. Efferent fiber degeneration and behavioral observations. Am J Anat 114:293-320.

Carpenter MB, Peter P (1972) Nigrostriatal and nigrothalamic fibers in the rhesus monkey. J Comp Neurol 144:93-116.

Carpenter MB, Strominger NL (1967) Efferent fiber projections of the subthalamic nucleus in the rhesus monkey. A comparison of the efferent projections of the subthalamic nucleus, substantia nigra, and globus pallidus. Am J Anat 121:41-72.

Carpenter MB, Nakano K, Kim R (1976) Nigrothalamic projections in the monkey demonstrated by autoradiographic techniques. J Comp Neurol 165:401-416.

Carpenter MB, Carleton SC, Keller JT (1981) Connections of the subthalamic nucleus in the monkey. Brain Res 224:1-19.

Chan-Palay V (1977) Cerebellar dentate nucleus. Organization, cytology and transmitters. Berlin: Springer.

Condé F (1987) Further studies on the use of the fluorescent tracers Fast Blue and Diamidino Yellow: effective uptake area and cellular storage sites. J Neurosci 7:31-43.

DeVito JL, Anderson ME (1982) An autoradiographic study of efferent connections of the globus pallidus in Macaca mulatta. Exp Brain Res 46:107-117.

Eidelberg E, Saldias CA (1960) A stereotaxic atlas for Cebus monkeys. J Comp Neurol 115:103-123.

Friedman HR, Goldman-Rakic PS (1994) Coactivation of prefrontal cortex and inferior parietal cortex in working memory tasks revealed by 2DG functional mapping in the rhesus monkey. J Neurosci 14:2775-2788.

Goldman-Rakic PS (1988) Topography of cognition: parallel distributed networks in primate association cortex. Annu Rev Neurosci 11:137-156.

Goldman-Rakic PS, Porrino LJ (1985) The primate mediodorsal (MD) nucleus and its projection to the frontal lobe. J Comp Neurol 242:535-560.

Gonzalo-Ruiz A, Leichnetz GR, Smith DJ (1988) Origin of cerebellar projections to the region of the oculomotor complex, medial pontine reticular formation, and superior colliculus in new world monkeys: a retrograde horseradish peroxidase study. J Comp Neurol 268:508-526.

Gottlieb JP, Bruce CJ, MacAvoy MG (1993) Smooth eye movements elicited by microstimulation in the primate frontal eye field. J Neurophysiol 69:786-799.

Gottlieb JP, MacAvoy MG, Bruce CJ (1994) Neural responses related to smooth-pursuit eye movements and their correspondence with electrically elicited smooth eye movements in the primate frontal eye field. J Neurophysiol 72:1634-1653.

Hardy SGP, Lynch JC (1992) The spatial distribution of pulvinar neurons that project to two subregions of the inferior parietal lobule in the macaque. Cereb Cortex 2:217-230.

Harting JK, Huerta MF, Frankfurter AJ, Strominger NL, Royce CJ (1980) Ascending pathways from the monkey superior colliculus: an autoradiographic analysis. J Comp Neurol 192:853-882.

Hikosaka O (1989) Role of basal ganglia in saccades. Rev Neurol 145:580-586.

Hikosaka O, Wurtz RH (1983a) Visual and oculomotor functions of monkey substantia nigra pars reticulata. I. Relation of visual and auditory responses to saccades. J Neurophysiol 49:1230-1253.

Hikosaka O, Wurtz RH (1983b) Visual and oculomotor functions of monkey substantia nigra pars reticulata. II. Visual responses related to fixation of gaze. J Neurophysiol 49:1254-1267.

Hikosaka O, Wurtz RH (1983c) Visual and oculomotor functions of monkey substantia nigra pars reticulata. III. Memory-contingent visual and saccade responses. J Neurophysiol 49:1268-1284.

Hikosaka O, Wurtz RH (1983d) Visual and oculomotor functions of monkey substantia nigra pars reticulata. IV. Relation of substantia nigra to superior colliculus. J Neurophysiol 49:1285-1301.

Hikosaka O, Wurtz RH (1989) The basal ganglia. In: The neurobiology 
of saccadic eye movements (Wurtz RH, Goldberg ME, eds), pp 257 281. Amsterdam: Elsevier.

Holmes G (1917) The symptoms of acute cerebellar injuries due to gunshot injuries. Brain 40:461-535.

Holsapple JW, Preston JB, Strick PL (1991) The origin of thalamic inputs to the "hand" representation in the primary motor cortex. J Neurosci 11:2644-2654.

Hoover JE, Strick PL (1993) Multiple output channels in the basal ganglia. Science 259:819-821.

Hotson JR, Langston EB, Lanston JW (1986) Saccade responses to dopamine in human MPTP-induced Parkinsonism. Ann Neurol 20:456-463.

Ilinsky IA, Kultas-Ilinsky K (1987) Sagittal cytoarchitectonic maps of the Macaca mulatta thalamus with a revised nomenclature of the motor-related nuclei validated by observations on their connectivity. J Comp Neurol 262:331-364.

Ilinsky IA, Jouandet ML, Goldman-Rakic PS (1985) Organization of the nigrothalamocortical system in the rhesus monkey. J Comp Neurol 236:315-330.

Jansen J, Brodal A (1940) Experimental studies on the intrinsic fibers of the cerebellum. II. The corticonuclear projection. J Comp Neurol 73:267-321.

Jansen J, Brodal A (1942) Experimental studies on the intrinsic fibers of the cerebellum. The cortico-nuclear projection in the rabbit and the monkey (Macaca rhesus). Avhandlinger utgitt av Det Norske Videnskaps-Acedemi i Oslo, I. Matematisk-Naturvidenskapelig Klasse $3: 1-50$.

Jones EG (1985) The thalamus. New York: Plenum.

Kalil K (1981) Projections of the cerebellar and dorsal column nuclei upon the thalamus of the rhesus monkey. J Comp Neurol 195:25-50.

Kato M, Miyashita N, Hikosaka O, Matsumura M, Usui S, Kori A (1995) Eye movements in monkeys with local dopamine depletion in the caudate nucleus. I. Deficits in spontaneous saccades. J Neurosci 15:912-927.

Keating EG (1991) Frontal eye field lesions impair predictive and visually-guided pursuit eye movements. Exp Brain Res 86:311-323.

Keizer K, Kuypers HGJM, Huisman AM, Dann O (1983) Diamidino yellow dihydrochloride (DY-2HCl), a new fluorescent retrograde neuronal tracer, which migrates only very slowly out of the cell. Exp Brain Res 51:179-191.

Keller EL (1989) The cerebellum. In: The neurobiology of saccadic eye movements (Wurtz RH, Goldberg ME, eds), pp 391-411. New York: Elsevier.

Keller EL, Heinen SJ (1991) Generation of smooth-pursuit eye movements: neuronal mechanisms and pathways. Neurosci Res 11:79-107.

Kievit J, Kuypers HGJ (1972) Fastigial cerebellar projections to the ventrolateral nucleus of the thalamus and the organization of the descending pathways. In: Corticothalamic projections and sensorimotor activities (Frigyesi T, Rinvik E, Yahr MD, eds), pp 91-114. New York: Raven.

Kim R, Nakano K, Jayaraman A, Carpenter MB (1976) Projections of the globus pallidus and adjacent structures: an autoradiographic study in the monkey. J Comp Neurol 169:263-290.

Klingberg T, O'Sullivan BT, Roland PE (1997) Bilateral activation of fronto-parietal networks by incrementing demand in a working memory task. Cereb Cortex 7:465-471.

Kori A, Miyashita N, Kato M, Hikosaka O, Usui S, Matsumura M (1995) Eye movements in monkeys with local dopamine depletion in the caudate nucleus. II. Deficits in voluntary saccades. J Neurosci 15:928-941.

Kuo J, Carpenter MB (1973) Organization of pallidothalamic projections in the rhesus monkey. J Comp Neurol 151:201-236.

Kusama T, Mabuchi M, Sumino T (1971) Cerebellar projections to the thalamic nuclei in monkeys. Proc Jpn Acad 47:505-510.

Kuypers HGJM, Bentivoglio M, Catsman-Berrevoets CE, Bharos AB (1980) Double retrograde neuronal labeling through divergent axon collaterals using two fluorescent tracers with the same excitation wavelength which label different features of the cell. Exp Brain Res 40:383-392.

Lasker AG, Zee DS, Hain TC, Folstein SE, Singer HS (1987) Saccades in Huntington's disease: initiation defects and distractibility. Neurology 37:364-370.

Lasker AG, Zee DS, Hain TC, Folstein SE, Singer HS (1988) Saccades in Huntington's disease: slowing and dysmetria. Neurology 38:427-431.

Leichnetz GR, Gonzalo-Ruiz A (1996) Prearcuate cortex in the Cebus monkey has cortical and subcortical connections like the macaque frontal eye field and projects to fastigial-recipient oculomotor-related brainstem nuclei. Brain Res Bull 41:1-29.

Leigh RJ, Zee DS (1991) The neurology of eye movements, 2nd Edition. Philadelphia: Davis.

Leigh RJ, Newman SA, Folstein SE, Lasker AG, Jensen BA (1983) Abnormal ocular motor control in Huntington's disease. Neurology 33:1268-1275.

Lisberger SG, Morris EJ, Tychsen L (1987) Visual motion processing and sensory-motor integration for smooth pursuit eye movement. Annu Rev Neurosci 10:97-129.

Lynch JC (1987) Frontal eye field lesions in monkeys disrupt visual pursuit. Exp Brain Res 68:437-441.

Lynch JC (1992) Saccade initiation and latency deficits after combined lesions of the frontal and posterior eye fields in monkeys. J Neurophysiol 68:1913-1916.

Lynch JC, Hoover JE, Strick PL (1994) Input to the primate frontal eye field from the substantia nigra, superior colliculus, and dentate nucleus demonstrated by transneuronal transport. Exp Brain Res 100:181-186.

MacAvoy MG, Gottlieb JP, Bruce CJ (1991) Smooth-pursuit eye movement representation in the primate frontal eye field. Cereb Cortex 1:95-102.

Manocha SL, Shantha TR, Bourne GH (1968) A stereotaxic atlas of the brain of the Cebus monkey (Cebus apella). Oxford: Oxford UP.

Matelli M, Luppino G (1996) Thalamic input to mesial and superior area 6 in the macaque monkey. J Comp Neurol 372:59-87.

Matelli M, Luppino G, Fogassi L, Rizzolatti G (1989) Thalamic input to inferior area 6 and area 4 in the macaque monkey. J Comp Neurol 280:468-488.

Matelli M, Luppino G, Rizzolatti G (1991) Architecture of superior and mesial area 6 and the adjacent cingulate cortex in the macaque monkey. J Comp Neurol 311:445-462.

Mesulam M-M (1990) Large-scale neurocognitive networks and distributed processing for attention, language, and memory. Ann Neurol 28:596-613.

Middleton FA, Strick PL (1994) Anatomical evidence for cerebellar and basal ganglia involvement in higher cognitive function. Science 266:458-461.

Nagao S (1992) Different roles of flocculus and ventral paraflocculus for oculomotor control in the primate. NeuroReport 3:13-16.

Nagao S, Nakamura N, Yamada J, Kitamura T (1992) Difference of afferent and efferent connections of monkey flocculus and ventral paraflocculus and its relevance to oculomotor functions. Soc Neurosci Abstr 18:854.

Nance DM, Burns J (1990) Fluorescent dextrans as sensitive anterograde neuroanatomical traces: applications and pitfalls. Brain Res Bull 25:139-145.

Nauta WJH, Mehler WR (1966) Projections of the lentiform nucleus in the monkey. Brain Res 1:3-42.

Noda H, Sugita S, Ikeda Y (1990) Afferent and efferent connections of the oculomotor region of the fastigial nucleus in the macaque monkey. J Comp Neurol 302:330-348.

Olszewski J (1952) The thalamus of Macaca mulatta. An atlas for use with the stereotaxic instrument. Basel: Karger.

Percheron G (1977) The thalamic territory of cerebellar afferents and the lateral region of the thalamus of the macaque in stereotaxic ventricular coordinates. J Hirnforsch 18:375-400.

Petit L, Clark VP, Ingeholm J, Haxby JV (1997) Dissociation of saccade-related and pursuit-related activation in human frontal eye fields as revealed by fMRI. J Neurophysiol 77:3386-3390.

Pierrot-Deseilligny C, Amarenco P, Roullet E, Martel R (1990) Vermal infarct with pursuit eye movement disorders. J Neurol Neurosurg Psychiatry 53:519-521.

Rouiller EM, Liang F, Babalian A, Moret V, Wiesendanger M (1994) Cerebellothalamocortical and pallidothalamocortical projections to the primary and supplementary motor cortical areas: a multiple tracing study in macaque monkeys. J Comp Neurol 345:185-213.

Schell GR, Strick PL (1984) The origin of thalamic inputs to the arcuate premotor and supplementary motor areas. J Neurosci 4:539-560.

Schlag J, Schlag-Rey M (1984) Visuomotor functions of central thalamus in monkey. II. Unit activity related to visual events, targeting, and fixation. J Neurophysiol 51:1175-1195.

Schlag J, Schlag-Rey M, Peck CK, Joseph J-P (1980) Visual responses of thalamic neurons depending on the direction of gaze and the position of targets in space. Exp Brain Res 40:170-184. 
Schlag-Rey M, Schlag J (1977) Visual and presaccadic neuronal activity in thalamic internal medullary lamina of cat: a study of targeting. J Neurophysiol 40:156-173.

Schlag-Rey M, Schlag J (1984) Visuomotor functions of central thalamus in monkey. I. Unit activity related to spontaneous eye movements. J Neurophysiol 51:1149-1195.

Schmued L, Kyriakidis K, Heimer L (1990) In vivo anterograde and retrograde axonal transport of the fluorescent rhodamine-dextranamine, Fluoro-Ruby, within the CNS. Brain Res 526:127-134.

Schobert E (1987) Telazol use in wild and exotic animals. Vet Med 82:1080-1088.

Selemon LD, Goldman-Rakic PS (1988) Common cortical and subcortical targets of the dorsolateral prefrontal and posterior parietal cortices in the rhesus monkey: evidence for a distributed neural network subserving spatially guided behavior. J Neurosci 8:4049-4068.

Shook BL, Schlag-Rey M, Schlag J (1991) Primate supplementary eye field. II. Comparative aspects of connections with the thalamus, corpus striatum, and related forebrain nuclei. J Comp Neurol 307:562-583.

Siwek DF, Pandya DN (1991) Prefrontal projections to the mediodorsal nucleus of the thalamus in the rhesus monkey. J Comp Neurol 312:509-524.

Stanton GB (1980) Topographical organization of ascending cerebellar projections from the dentate and interposed nuclei in Macaca mulatta: an anterograde degeneration study. J Comp Neurol 190:699-731.

Starr A (1967) A disorder of rapid eye movements in Huntington's chorea. Brain 90:545-564.

Tian J-R, Lynch JC (1995) Slow and saccadic eye movements evoked by microstimulation in the supplementary eye field of Cebus monkey. J Neurophysiol 74:2204-2210.
Tian J-R, Lynch JC (1996a) Functionally defined smooth and saccadic eye movement subregions in the frontal eye field of Cebus monkeys. J Neurophysiol 76:2740-2753.

Tian J-R, Lynch JC (1996b) Cortico-cortical input to the smooth and saccadic eye movement subregions of the frontal eye field in Cebus monkeys. J Neurophysiol 76:2754-2771.

Tian J-R, Zee DS, Lasker AG, Folstein SE (1991) Saccades in Huntington's disease: predictive tracking and interaction between release of fixation and initiation of saccades. Neurology 41:875-881.

Tian J-R, Liu H, Lynch JC (1995) Thalamic input to the slow eye movement and saccadic eye movement subregions of the frontal eye field in Cebus monkey. Soc Neurosci Abstr 21:1195.

Vogt C, Vogt O (1919) Allgemeinere ergebnisse unserer hirnforschung. J Psychol Neurol (Leipzig) 25:277-462.

Walker AE (1940) A cytoarchitectural study of the prefrontal area of the macaque monkey. J Comp Neurol 98:59-86.

Westheimer G, Blair SM (1973) Oculomotor deficits in cerebellectomized monkeys. Invest Ophthal 12:618-621.

White OB, Saint-Cyr JA, Tomlinson RD, Sharpe JA (1983) Ocular motor deficits in Parkinson's disease. II. Control of the saccadic and smooth pursuit systems. Brain 106:571-587.

Yamamoto T, Yoshida K, Roshikawa H, Kishimoto Y, Oka H (1992) The medial dorsal nucleus is one of the thalamic relays of the cerebellocerebral responses to the frontal association cortex in the monkey: horseradish and fluorescent dye double staining study. Brain Res 579:315-320.

Zee DS (1982) Ocular motor control: cerebellum. In: Neuroophthalmology (Lessell S, Van Dalen JTW, eds), pp 136-147. Amsterdam: Excerpta Medica. 